\title{
Retrieval of carbon dioxide vertical profiles from solar occultation observations and associated error budgets for ACE-FTS and CASS-FTS
}

\author{
C. E. Sioris ${ }^{1}$, C. D. Boone ${ }^{2}$, R. Nassar ${ }^{3}$, K. J. Sutton ${ }^{4}$, I. E. Gordon ${ }^{5}$, K. A. Walker ${ }^{6}$, and P. F. Bernath \\ ${ }^{1}$ Department of Earth and Space Science and Engineering, York University, Toronto, ON, Canada \\ ${ }^{2}$ Department of Chemistry, University of Waterloo, Waterloo, ON, Canada \\ ${ }^{3}$ Climate Research Division, Environment Canada, Toronto, ON, Canada \\ ${ }^{4}$ Department of Physics and Astronomy, University of Waterloo, Waterloo, ON, Canada \\ ${ }^{5}$ Atomic and Molecular Physics Division, Harvard-Smithsonian Center for Astrophysics, Cambridge, MA, USA \\ ${ }^{6}$ Department of Physics, University of Toronto, Toronto, ON, Canada \\ ${ }^{7}$ Department of Chemistry and Biochemistry, Old Dominion University, Norfolk, VA, USA
}

Correspondence to: C. E. Sioris (csioris@cfa.harvard.edu)

Received: 5 February 2014 - Published in Atmos. Meas. Tech. Discuss.: 18 February 2014

Revised: 22 May 2014 - Accepted: 8 June 2014 - Published: 22 July 2014

\begin{abstract}
An algorithm is developed to retrieve the vertical profile of carbon dioxide in the 5 to $25 \mathrm{~km}$ altitude range using mid-infrared solar occultation spectra from the main instrument of the ACE (Atmospheric Chemistry Experiment) mission, namely the Fourier transform spectrometer (FTS). The main challenge is to find an atmospheric phenomenon which can be used for accurate tangent height determination in the lower atmosphere, where the tangent heights (THs) calculated from geometric and timing information are not of sufficient accuracy. Error budgets for the retrieval of $\mathrm{CO}_{2}$ from ACE-FTS and the FTS on a potential follow-on mission named CASS (Chemical and Aerosol Sounding Satellite) are calculated and contrasted. Retrieved THs have typical biases of $60 \mathrm{~m}$ relative to those retrieved using the ACE version 3.x software after revisiting the temperature dependence of the $\mathrm{N}_{2}$ CIA (collision-induced absorption) laboratory measurements and accounting for sulfate aerosol extinction. After correcting for the known residual high bias of ACE version 3.x THs expected from $\mathrm{CO}_{2}$ spectroscopic/isotopic inconsistencies, the remaining bias for tangent heights determined with the $\mathrm{N}_{2} \mathrm{CIA}$ is $-20 \mathrm{~m} . \mathrm{CO}_{2}$ in the 5-13 km range in the 2009-2011 time frame is validated against aircraft measurements from CARIBIC (Civil Aircraft for the Regular Investigation of the atmosphere Based on an Instrument Container), CONTRAIL (Comprehensive Observation Network for Trace gases by Airline), and HIPPO
\end{abstract}

(HIAPER Pole-to-Pole Observations), yielding typical biases of $-1.7 \mathrm{ppm}$ in the $5-13 \mathrm{~km}$ range. The standard error of these biases in this vertical range is $0.4 \mathrm{ppm}$. The multiyear ACE-FTS data set is valuable in determining the seasonal variation of the latitudinal gradient which arises from the strong seasonal cycle in the Northern Hemisphere troposphere. The annual growth of $\mathrm{CO}_{2}$ in this time frame is determined to be $2.6 \pm 0.4 \mathrm{ppm}_{\text {year }}{ }^{-1}$, in agreement with the currently accepted global growth rate based on ground-based measurements.

\section{Introduction}

Besides water vapor, carbon dioxide is the most important greenhouse gas. Its concentration in the atmosphere has been rising at an increasing rate for decades (Hofmann et al., 2009), with a rate of $1.66-2.44$ ppm year $^{-1}$ in the 20092012 period for the background global mean (http://www. esrl.noaa.gov/gmd/ccgg/trends/global.html). There is growing global concern about the consequential climate change with its broad spectrum of impacts on life across the planet. Efforts to curb the atmospheric growth of this greenhouse gas are difficult because of its long atmospheric lifetime and our dependence on fossil fuels. Nonetheless, a thorough scientific understanding of the budget of $\mathrm{CO}_{2}$, a gas innate to 
life on this planet, is needed. To address this need, a wide range of measurements (concentrations, fluxes, isotopes) and modeling tools are being developed. Satellite-based remote sensing provides a global view, although the vertical distribution of $\mathrm{CO}_{2}$, which is a very important piece of observational information, is sparse or lacking. $\mathrm{CO}_{2}$ volume mixing ratio (VMR) profiles in the mesosphere (above $\sim 70 \mathrm{~km}$ ) and lower thermosphere have been retrieved globally from observations by the Atmospheric Chemistry Experiment - Fourier transform spectrometer (ACE-FTS) where tangent heights are determined from geometric information (Beagley et al., 2009; Emmert et al., 2011). Because this approach is generally not of sufficient quality in the lower stratosphere and troposphere to measure $\mathrm{CO}_{2}$, limb-viewing thermal infrared sounders such as the Michelson Interferometer for Passive Atmospheric Sounding (MIPAS, Fischer et al., 2008) and High Resolution Dynamics Limb Sounder (HIRDLS, Gille et al., 2008) use $\mathrm{CO}_{2}$ simply for tangent height and temperature determination and sacrifice the opportunity to measure the VMR profile.

This was also the case with ACE-FTS until recently (Foucher et al., 2009). ACE-FTS is onboard SCISAT, a satellite in a low Earth orbit, which was launched in August 2003. The measurements are performed at sunrise and sunset using the solar occultation technique, which, by the design of the experiment, provides the following three advantages which ultimately translate into retrieval accuracy:

1. high signal-to-noise ratio,

2. self-calibration, and

3. a single, geometric path length at each tangent height.

The spectral range is $750-4400 \mathrm{~cm}^{-1}(2.3-13.3 \mu \mathrm{m})$ and the spectral resolution is $0.02 \mathrm{~cm}^{-1}$. The orbital inclination of $74^{\circ}$ results in better coverage of high latitudes, but the tropics are probed in four different months of the year, covering the four seasons. More than a decade after launch, ACEFTS continues to have a signal-to-noise ratio (SNR) of $\sim 400$ in the $4 \mu \mathrm{m}$ region, as determined by analysis of spectra at the highest tangent heights $(130-150 \mathrm{~km})$. In the other relevant spectral region $(7 \mu \mathrm{m})$, the SNR is 300 to 400 (e.g., Châteauneuf et al., 2005).

In this work, we improve the retrieval of vertical profiles particularly via major improvements to the tangent height determination. We also perform comprehensive error budgets for ACE-FTS and the FTS on the proposed CASS (Chemical and Aerosol Sounding Satellite) mission (Melo et al., 2013).

\section{Method}

Retrieval of $\mathrm{CO}_{2}$ and tangent height in this work builds on previous algorithm development by Boone et al. (2005), Foucher (2009), Foucher et al. (2009, 2011), and Rinsland et al. (2010). As discussed by Boone et al. (2005), below $\sim 43 \mathrm{~km}$, tangent heights (THs) cannot be accurately determined from the geometric information (satellite position and instrument viewing angle) and thus atmospheric observables are exploited for this purpose. The ACE version 2.2 (v2.2) and v3.x (v3.0 and v3.5) retrieval algorithms (Boone et al., 2005, 2013) use $\mathrm{CO}_{2}$ absorption lines, but the retrieval problem becomes circular if one wants to retrieve $\mathrm{CO}_{2}$ VMR using THs determined with absorption by this molecule. Other atmospheric molecules which have thermal infrared absorption and could possibly be used for tangent height determination include $\mathrm{O}_{2}$ and $\mathrm{N}_{2}$ because their VMRs are well known, and constant through the troposphere and stratosphere. The $\mathrm{O}_{2}$ magnetic dipole and electric quadrupole vibrational fundamental bands, the $\mathrm{N}_{2}$ electric quadrupole vibrational fundamental, and the $\mathrm{O}_{2}$ and $\mathrm{N}_{2}$ collision-induced absorption (CIA) vibrational fundamentals are essentially the five options excluding $\mathrm{CO}_{2}$. In theory, the $\mathrm{O}_{2}$ and $\mathrm{N}_{2}$ lines would be preferable to $\mathrm{N}_{2}$ CIA because there would be no bias due to non-opaque clouds and the upper altitude would be much higher (e.g., $48 \mathrm{~km}$ for $\mathrm{N}_{2}$ quadrupole versus $\sim 25 \mathrm{~km}$ for $\mathrm{N}_{2}$ CIA). If we could demonstrate that the VMR of $\mathrm{N}_{2}$ could be retrieved accurately using its quadrupole lines, then one would expect that tangent heights retrieved from these lines would also be accurate. However, even though nonlocal thermodynamic equilibrium in $\mathrm{N}_{2}$ absorption measurements below $35 \mathrm{~km}$ is expected to be a small-to-negligible effect (e.g., Goldman et al., 2007), the retrieval of $\mathrm{N}_{2}$ from the quadrupole line does not have the necessary precision and suffers from a low bias at the lowest altitudes. We were able to improve the $\mathrm{N}_{2}$ VMR retrieval from the quadrupole lines compared to those retrieved using the ACE-FTS v3.x algorithm by adding lines with higher rotational quantum numbers, but ultimately the retrieval remained significantly biased relative to the expected $78 \% \mathrm{VMR}$ of $\mathrm{N}_{2}$ (see also Goldman et al., 2007); the $\mathrm{N}_{2}$ line parameters are not satisfactory. Regarding $\mathrm{O}_{2}$, we found that the retrieval could not be extended below $15 \mathrm{~km}$ because of saturating $\mathrm{H}_{2} \mathrm{O}$ lines, and therefore the $\mathrm{O}_{2}$ magnetic dipole and electric quadrupole lines did not meet our goal of retrieving into the troposphere globally. This same interference would affect a TH retrieval using the $\mathrm{O}_{2}$ CIA.

ACE-FTS has a circular field of view of $1.25 \mathrm{mrad}$ with a diameter of 3 to $4 \mathrm{~km}$ at the tangent point. Vertical sampling distance is dependent on the tangent height and the angle between the satellite velocity vector and the line-ofsight, namely the beta angle. In the troposphere and lowermost stratosphere, the vertical sampling is typically $\sim 1 \mathrm{~km}$. ACE-FTS profiles are not perfectly vertical since the satellite motion results in a difference in the satellite position for each tangent point. For low beta angles, the horizontal displacement of the tangent point during a limb scan is negligible, but for high beta angles, it can reach $400 \mathrm{~km}$ over the $5-25 \mathrm{~km}$ altitude range. 
Table 1. $\mathrm{N}_{2}$ CIA microwindows: Center frequencies, widths, and tangent height ranges in order of increasing lower TH limit.

\begin{tabular}{lrrr}
\hline $\begin{array}{l}\text { center } \\
\text { frequency } \\
\left(\mathrm{cm}^{-1}\right)\end{array}$ & $\begin{array}{r}\text { microwindow } \\
\text { width } \\
\left(\mathrm{cm}^{-1}\right)\end{array}$ & $\begin{array}{r}\text { lower } \\
\text { TH } \\
(\mathrm{km})\end{array}$ & $\begin{array}{r}\text { upper } \\
\text { TH } \\
(\mathrm{km})\end{array}$ \\
\hline 2500.70 & 3.50 & 5 & 10 \\
2505.50 & 3.00 & 5 & 15 \\
2500.70 & 3.00 & 10 & 15 \\
2492.10 & 2.00 & 10 & 18 \\
2489.73 & 0.46 & 13 & 18 \\
2485.10 & 0.60 & 13 & 20 \\
2480.33 & 0.16 & 14 & 22 \\
2473.02 & 0.23 & 15 & 22 \\
2463.90 & 0.24 & 15 & 22 \\
2462.00 & 1.60 & 15 & 23 \\
2439.94 & 0.40 & 18 & 24 \\
2430.21 & 0.80 & 21 & 25 \\
\hline
\end{tabular}

The modified global fitting method is used (Boone et al., 2005), and tangent heights are retrieved simultaneously with $\mathrm{CO}_{2}$ VMRs. The ACE-FTS v3.x retrieval software was adapted for this application. One of the main modifications was to fit the scale and slope parameters (Boone et al., 2005) for the microwindows targeting $\mathrm{CO}_{2}$ but not for the microwindows targeting $\mathrm{N}_{2}$ CIA.

Considering all of the microwindows listed in Tables 1-2 below, the significant interferers are ${ }^{18} \mathrm{O}^{12} \mathrm{C}^{16} \mathrm{O},{ }^{17} \mathrm{O}^{12} \mathrm{C}^{16} \mathrm{O}$, ${ }^{12} \mathrm{CH}_{4},{ }^{13} \mathrm{CH}_{4},{ }^{14} \mathrm{~N}^{14} \mathrm{~N}^{16} \mathrm{O},{ }^{15} \mathrm{~N}^{14} \mathrm{~N}^{16} \mathrm{O},{ }^{14} \mathrm{~N}^{14} \mathrm{~N}^{18} \mathrm{O}, \mathrm{H}_{2}{ }^{17} \mathrm{O}$, and HDO. For these species, the vertical profiles of VMR, normalized by their standard natural isotopic abundance, are assumed to be equal to the VMR of their respective primary isotopologue, recovered using version 3.x of the ACE-FTS retrieval software (Boone et al., 2013). The sensitivity to this assumption is checked as part of the error budget (Sect. 2.3).

\section{1 $\mathrm{N}_{2}$ CIA modelling and uncertainties}

The Lafferty et al. (1996) $\mathrm{N}_{2}$ CIA cross-section spectra measured in the laboratory at five temperatures are considered to be the best available for temperatures below $300 \mathrm{~K}$ according to Richard et al. (2012). The stated uncertainties in the Lafferty et al. (1996) absorption coefficients are in the $0.71 \%$ to $0.9 \%$ range if the uncertainty in the background spectra is added in quadrature to the uncertainty from the absorption spectra. Menoux et al. (1993) state the uncertainty in their measurements above $2470 \mathrm{~cm}^{-1}$ rises from $5 \%$ (near the band center) to $10 \%$. The empirical model proposed by Lafferty et al. (1996) is:

$B(\nu, T)=B_{0}(v) \exp \left[\beta_{0}(v)\left(1 / T_{0}-1 / T\right)\right]$

where $v$ is the wavenumber $\left(\mathrm{cm}^{-1}\right), T$ is the temperature $(\mathrm{K})$, and $T_{0}$ is the reference temperature of $296 \mathrm{~K}$. $B_{0}$ and $\beta_{0}$ are the model parameters which are independent and dependent
Table 2. $\mathrm{CO}_{2}$ microwindows: Center frequencies, widths, and tangent height ranges in order of increasing center frequency.

\begin{tabular}{|c|c|c|c|}
\hline $\begin{array}{l}\text { center frequency } \\
\left(\mathrm{cm}^{-1}\right)\end{array}$ & $\begin{array}{l}\text { width } \\
\left(\mathrm{cm}^{-1}\right)\end{array}$ & $\begin{array}{r}\text { lower TH } \\
(\mathrm{km})\end{array}$ & $\begin{array}{r}\text { upper TH } \\
(\mathrm{km})\end{array}$ \\
\hline 1371.80 & 0.30 & 15 & 25 \\
\hline 1372.52 & 0.30 & 20 & 25 \\
\hline 1379.25 & 0.30 & 15 & 20 \\
\hline 1380.70 & 0.35 & 15 & 25 \\
\hline 1383.65 & 0.40 & 17 & 25 \\
\hline 1384.42 & 0.45 & 15 & 25 \\
\hline 1385.90 & 0.35 & 15 & 25 \\
\hline 2604.50 & 0.80 & 5 & 25 \\
\hline 2609.80 & 0.45 & 5 & 20 \\
\hline 2610.56 & 0.20 & 5 & 20 \\
\hline 2611.30 & 0.35 & 5 & 20 \\
\hline 2612.04 & 0.20 & 5 & 25 \\
\hline 2616.45 & 0.20 & 6 & 25 \\
\hline 2617.18 & 0.20 & 7 & 20 \\
\hline 2620.11 & 0.16 & 8 & 20 \\
\hline 2620.83 & 0.18 & 5 & 20 \\
\hline 2621.50 & 0.35 & 15 & 25 \\
\hline 2623.75 & 0.30 & 15 & 20 \\
\hline 2624.46 & 0.16 & 8 & 25 \\
\hline 2625.18 & 0.16 & 8 & 20 \\
\hline 2626.63 & 0.20 & 5 & 20 \\
\hline 2627.35 & 0.20 & 5 & 25 \\
\hline 2629.50 & 0.18 & 5 & 25 \\
\hline 2629.50 & 0.20 & 8 & 25 \\
\hline 2632.36 & 0.20 & 7 & 25 \\
\hline 2633.79 & 0.20 & 8 & 25 \\
\hline 2636.63 & 0.35 & 5 & 25 \\
\hline
\end{tabular}

on temperature, respectively. $B_{0}$ represents the absorption coefficient of $\mathrm{N}_{2}-\mathrm{N}_{2}$ at $296 \mathrm{~K}$ while $\beta_{0}$ represents its temperature dependence at this reference temperature. In reality, $\beta_{0}$ is determined using the spectra at five different temperatures in the range $228.2-272.1 \mathrm{~K}$ available in the highresolution transmission (HITRAN) 2012 database (Rothman et al., 2013), and the empirical law in Eq. (1). We determine the best $\beta_{0}(v)$ on the $0.25 \mathrm{~cm}^{-1}$ grid of the Lafferty et al. (1996) measurements by absolute difference minimization of Eq. (1) at each wavenumber increment independently. This involves interpolating $B_{0}(v)$ from Table 1 of Lafferty et al. (1996) to the $0.25 \mathrm{~cm}^{-1}$ grid. We then average the best $\beta_{0}(v)$ in $5 \mathrm{~cm}^{-1}$ bins in the 2130 to $2600 \mathrm{~cm}^{-1}$ range to reduce noise. This results in the pink curve in Fig. 1. In order to test the precision of the empirical model, we obtain five spectral simulations of $B_{0}$ by dividing the five observed $B(T)$ spectra by the exponential function on the right hand side of Eq. (1) inserting the appropriate $T$ in each case as well as the best-fit $\beta_{0}$ spectrum (obtained using the spectra at all five temperatures). The standard deviation of the five $B_{0}(v)$ spectra is a measure of the consistency of the observed spectra and also reflects any inaccuracy in the empirical model. 


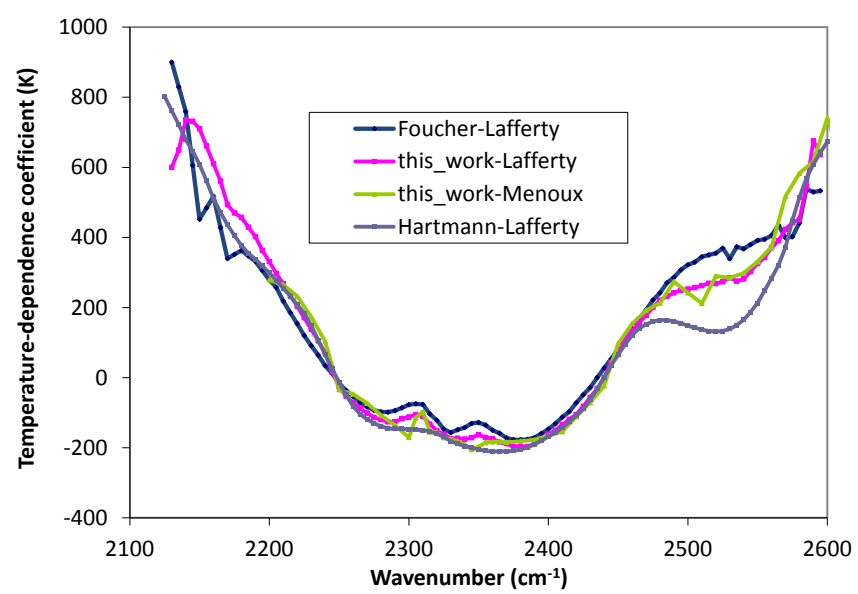

Figure 1. Temperature dependence of $\mathrm{N}_{2}$ CIA determined using the empirical model of Lafferty et al. (1996). The pink squares were determined in this work, while previous attempts were made by Hartmann (Lafferty et al., 1996) in blue-grey and Foucher (2009) in dark blue using the same data set. Also shown in green is the temperature-dependence model parameter determined here using the less precise measurements of Menoux et al. (1993).

The relative uncertainties in $B_{0}$ based on the standard deviation is similar to the quoted uncertainty (see above), except that at the low and high $\left(v>2480 \mathrm{~cm}^{-1}\right)$ frequency ends of the band, the relative uncertainty clearly exceeds $1 \%$, similar to the frequency-dependence of the uncertainty found by Menoux et al. (1993).

We also determined the temperature dependence from the data set provided by Menoux et al. (1993) but it did not improve the retrieved tangent heights when applied for wavenumbers $\leq 2600 \mathrm{~cm}^{-1}$ (the upper limit of Lafferty's published measurements). We use the Menoux et al. (1993) measurements to determine the density-normalized $\mathrm{N}_{2}-\mathrm{N}_{2}$ CIA coefficients at $296 \mathrm{~K}$ and their temperature dependence (following Lafferty et al., 1996) in order to extend the $\mathrm{N}_{2}$ CIA empirical model out to $2640 \mathrm{~cm}^{-1}$. The temperaturedependence spectra that we obtained independently using the Menoux et al. (1993) and Lafferty et al. (1996) $\mathrm{N}_{2}$ CIA spectra are more consistent, particularly near $2500 \mathrm{~cm}^{-1}$, than the temperature-dependence spectra obtained previously (Lafferty et al., 1996; Foucher, 2009) as shown in Fig. 1.

For this work, we have applied a uniform increase to the $B_{0}$ spectrum of Lafferty et al. (1996) of $0.9 \%$ and additionally by $0.1 \%$ and $0.2 \%$ at 2500 and $2505-2510 \mathrm{~cm}^{-1}$, respectively. These increases are within the uncertainties stated by Lafferty et al. (1996) (discussed above) or the variation of the five $B_{0}$ estimates as a function of wavelength.

Lafferty et al. (1996) published the following fit to the temperature dependence of the relative $\mathrm{N}_{2}$ collision efficiency with $\mathrm{O}_{2}$ versus collision with itself $\left(\mathrm{N}_{2}\right)$ of

$E_{\mathrm{O}_{2} / \mathrm{N}_{2}}^{\mathrm{N}_{2}}(T)=1.294-0.4545 T / T_{0}$.

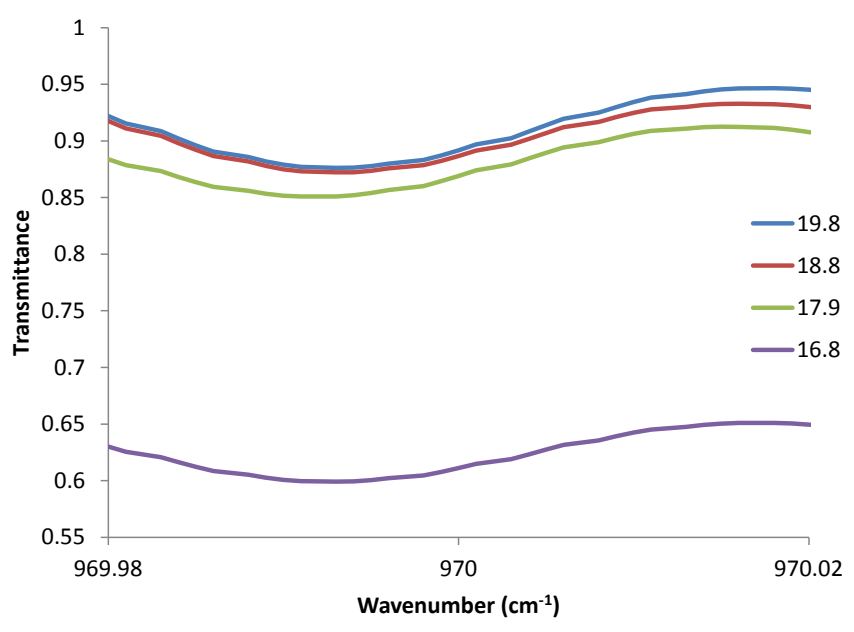

Figure 2. Observed transmittance spectra in the vicinity of the wavenumber used for cloud detection $\left(970.00 \mathrm{~cm}^{-1}\right)$ at a series of THs listed in the legend (in $\mathrm{km}$ ) during sunrise $29818\left(8^{\circ} \mathrm{S}, 67^{\circ} \mathrm{E}\right)$ on 24 February 2009. The sharp decrease in transmittance between THs of 16.8 and $17.9 \mathrm{~km}$ is due to cloud opacity at the former.

Absorption due to $\mathrm{N}_{2}-\mathrm{H}_{2} \mathrm{O}$ collisional complexes (Baranov et al., 2012) is neglected. This is a safe assumption for the upper troposphere and lower stratosphere where water vapor is typically $<0.1 \%$ of air by volume. Using Eqs. (1)-(2) and the temperature dependence shown in Fig. 1, as well as 0.7808 and 0.2095 for the VMRs of $\mathrm{N}_{2}$ and $\mathrm{O}_{2}$, we obtained a slightly modified version of Eq. (8) of Lafferty et al. (1996).

\subsection{Retrieval setup and microwindows}

The HITRAN 2012 database (Rothman et al., 2013) is used in this work whereas ACE v3.x relies on HITRAN 2004 (with some updates) (Boone et al., 2013).

Microwindows have one of four targets:

1. clouds

2. $\mathrm{TH}$ (via $\mathrm{N}_{2}$ CIA)

3. $\mathrm{CO}_{2}$

4. aerosol extinction.

\subsubsection{Cloud detection}

Cloud detection is carried out as a pre-processing step before the $\mathrm{CO}_{2}$ profile retrieval. Following Foucher (2009), observed spectral transmittance profiles at 970 and $2505.5 \mathrm{~cm}^{-1}$ are used for cloud detection. Figures 2 and $3 \mathrm{a}$ show these respective spectral regions. Microwindow widths are narrow so that each cloud microwindow consists of a single point (to speed up processing). No spectral averaging is necessary. Only tangent heights below $20.0 \mathrm{~km}$ are searched for clouds. At $970 \mathrm{~cm}^{-1}$, when the transmittance falls below 0.8 or when the change in transmittance between 


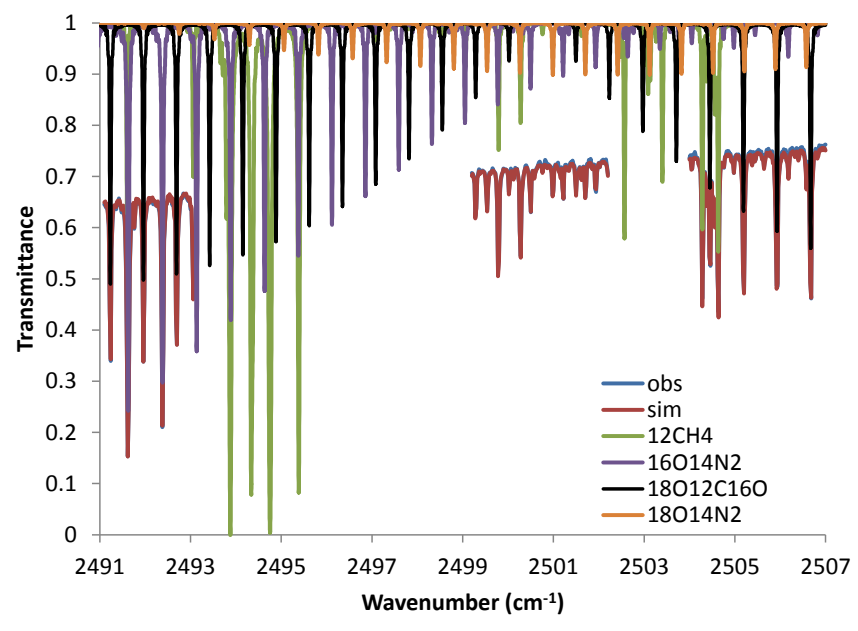

Figure 3a. Observed ("obs") and simulated ("sim") transmittance at $\mathrm{TH}=12.46 \mathrm{~km}$ for sunrise $39035\left(53^{\circ} \mathrm{S}, 18^{\circ} \mathrm{W}\right)$ on 12 November 2010 for the three microwindows targeting the $\mathrm{N}_{2}$ CIA at that tangent height. Spectral lines for other relevant species in the region are also shown.

adjacent tangent heights exceeds an empirically determined value of 0.0689 , a cloud is assumed to be present. Similarly at $2505.5 \mathrm{~cm}^{-1}$, if the change in transmittance between adjacent tangent heights exceeds 0.076 , a cloud is assumed to be present. Foucher (2009) used 0.1 as a threshold for both cloud microwindows. The $\mathrm{CO}_{2}$ retrieval is not applied to cloudy occultations. These empirical settings are very stringent for the purpose of reducing cloud-related error in the determination of THs to a level where it is not a dominant source of $\mathrm{CO}_{2}$ retrieval error (see Sect. 2.3). Some false positives may be present (i.e., occultation is flagged as cloudy when it is not). Out of 16676 available occultations in the 2009-2011 time period, $77 \%$ are deemed to be cloudy and not processed and an additional $15 \%$ are cloudy only at $2505.5 \mathrm{~cm}^{-1}$ and are processed (see below). The remaining $8 \%$ constitute the cloud-free data set.

\subsubsection{Tangent heights}

To retrieve tangent heights via the $\mathrm{N}_{2}$ CIA, we use the 12 microwindows in Table 1 . For the microwindows at $2505,2492.1$, and $2462 \mathrm{~cm}^{-1}$, the central frequencies and widths were specified in Foucher et al. (2009). The center frequencies for the first and third microwindows were obtained via private communication with Foucher. Foucher et al. (2011) mentioned the use of a microwindow at $2430 \mathrm{~cm}^{-1}$. We have optimized the microwindow center and width in terms of interfering absorption. We find that the tangent heights retrieved using the microwindow at $2462 \mathrm{~cm}^{-1}$ were inconsistent with those retrieved from higher frequencies $\left(>2492 \mathrm{~cm}^{-1}\right)$. To remedy this likely spectroscopic issue, we have added five narrow microwindows within this $30 \mathrm{~cm}^{-1}$ gap to help smoothly transition between these two

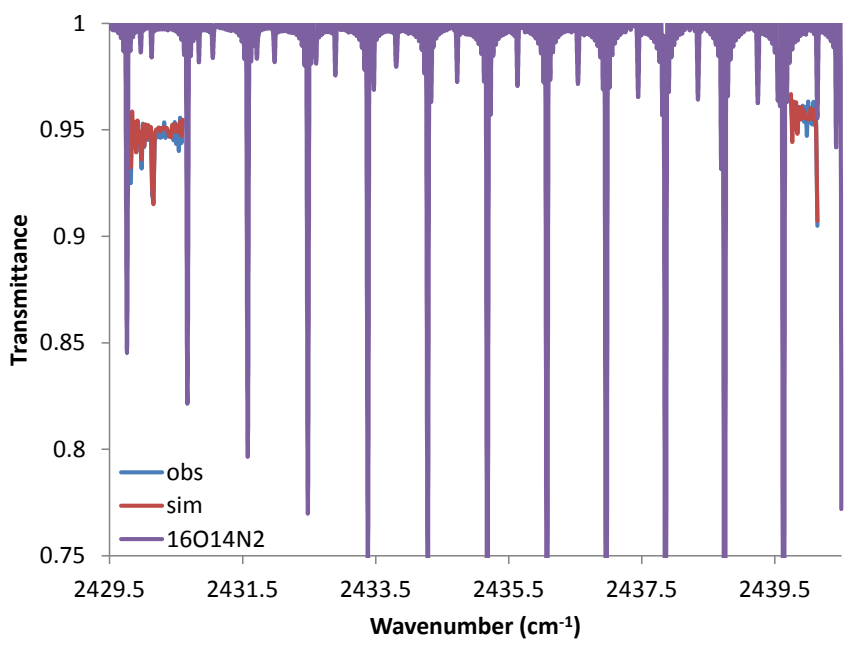

Figure 3b. Same as Fig. 3a, except for $\mathrm{TH}=23.72 \mathrm{~km}$, at which tangent height, two $\mathrm{N}_{2}$ CIA microwindows are used.

inconsistent microwindows. In choosing these narrow microwindows, we avoided strong lines due to ${ }^{14} \mathrm{~N}^{14} \mathrm{~N}^{16} \mathrm{O}$, ${ }^{14} \mathrm{~N}^{14} \mathrm{~N}^{18} \mathrm{O}$, and ${ }^{12} \mathrm{CH}_{4}$ so that the depth due to absorption at the line center is $<7.5 \%$ (at ACE-FTS resolution) for any remaining lines for the tangent height ranges given in Table 1. It is clear that Foucher et al. $(2009,2011)$ also avoided strong interfering absorption since the microwindow centered at $2462 \mathrm{~cm}^{-1}$ lies in the band center of the $v_{1}+2 v_{2}$ band of ${ }^{14} \mathrm{~N}_{2}{ }^{16} \mathrm{O}$ (which does not have a $Q$ branch), and the microwindow at $2500.7 \mathrm{~cm}^{-1}$ lies in between the $2 v_{1}$ and $v_{1}+2 v_{2}$ bands of ${ }^{14} \mathrm{~N}_{2}{ }^{16} \mathrm{O} . \mathrm{N}_{2} \mathrm{O}$ is an important interferer in between these two frequencies, with transmittance between adjacent lines not reaching $100 \%$ due to overlapping wings. We have modified the combined range of the $12 \mathrm{~N}_{2}$ CIA microwindows to span from 5 to $25 \mathrm{~km}$. Figure $3 \mathrm{a}$ and b illustrate the microwindows used for tangent height determination at a low and high $\mathrm{TH}$, respectively.

Since the first guess for tangent heights comes from ACE v3.x data, it is important to consider the finding of Foucher (2009) that there was a discontinuity at $12 \mathrm{~km}$ in ACE v2.2 data with regard to the altitudes, temperatures, and pressures obeying hydrostatic equilibrium. This discontinuity is located at the transition between pressure and temperature $(p, T)$ data retrieved from ACE-FTS and obtained from the assimilated meteorological fields provided by the Canadian Meteorological Centre (CMC). However, we searched for such a discontinuity in the v3.x data in the lower atmosphere, and found that the atmospheric $p$ and $T$, and altitudes obey hydrostatic equilibrium with no apparent discontinuity at the altitude of this transition.

\subsection{3 $\mathrm{CO}_{2}$}

For $\mathrm{CO}_{2}$ retrieval, we have relied exclusively on ${ }^{18} \mathrm{O}^{12} \mathrm{C}^{16} \mathrm{O}$ lines to avoid any isotopic abundance inconsistencies that 


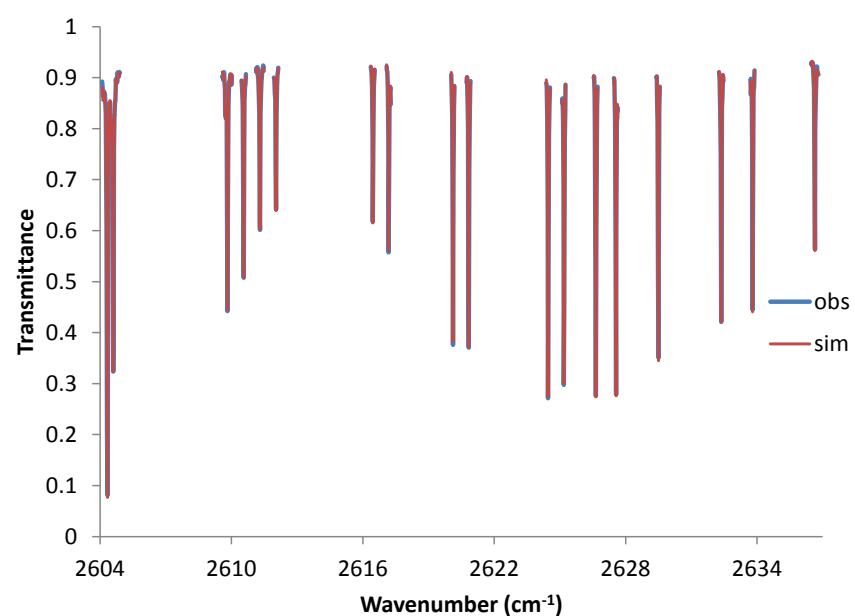

Figure 3c. Same as Fig. 3a, but for microwindows targeting lines in the $20002 \leftarrow 00001$ band of ${ }^{18} \mathrm{O}^{12} \mathrm{C}^{16} \mathrm{O}$.

would arise with multiple $\mathrm{CO}_{2}$ isotopologues. Low- $J$ lines of the $20002 \leftarrow 00001$ band of ${ }^{18} \mathrm{O}^{12} \mathrm{C}^{16} \mathrm{O}$ from both the $P$ and $R$ branches are used. Specifically, in the $P$ branch, the selected lines correspond to $3 \leq J \leq 6$. In the $R$ branch, the selected lines correspond to $2 \leq J \leq 30$.. At $J=30$, the lower state energy is $342.3089 \mathrm{~cm}^{-1}$ and thus $R$ branch transitions for an initial rotation quantum number of $J \leq 30$ are weakly sensitive to temperature (Foucher, 2009). Any significant ${ }^{18} \mathrm{O}^{12} \mathrm{C}^{16} \mathrm{O}$ lines in the $\mathrm{N}_{2}$ CIA microwindows have lower state energies of $<300 \mathrm{~cm}^{-1}$ and thus serve to increase the temperature-insensitive $\mathrm{CO}_{2}$ signal. To increase the $\mathrm{CO}_{2}$ signal at the higher altitudes, we included seven low- $J$ lines in the $1371-1386 \mathrm{~cm}^{-1}$ region $(10001 \leftarrow 00001)$ with microwindow settings from the ACE v3.x retrieval of ${ }^{18} \mathrm{OC}^{16} \mathrm{O}$. Information on all $27 \mathrm{CO}_{2}$ microwindows is in Table 2. Figure $3 \mathrm{c}$ and $\mathrm{d}$ show the $\mathrm{CO}_{2}$ microwindows used at a low and high TH in the region of the $20002 \leftarrow 00001$ band of ${ }^{18} \mathrm{O}^{12} \mathrm{C}^{16} \mathrm{O}$, respectively. The line intensities in the HITRAN 2012 spectroscopic database are from a model for both the $v_{1}$ fundamental and the $20002 \leftarrow 00001$ band. Because the line intensity uncertainties in HITRAN 2012 are conservatively set to $>20 \%$ for all lines mentioned above, we have compared the line intensities to ones measured in the laboratory (Toth, 1985; Teffo et al., 2003; Malathy Devi et al., 1984) to serve as an alternative estimate of their uncertainty. To summarize, the agreement on the line intensities in the $10001 \leftarrow 00001$ band is $<1 \%$, except for the weakest line at $1371.757715 \mathrm{~cm}^{-1}$ which differs by $1.6 \%$; however, the semi-empirical model relies on Toth's measurements (Teffo et al., 2002), so the validation is far from independent and the measurements have never been repeated to our knowledge. For the $20002 \leftarrow 00001$ band, the agreement is not as good, with the standard deviation of relative differences being $2.5 \%$ and the mean bias being $-2.2 \%$ (i.e., HITRAN 2012 line intensities are lower than those measured

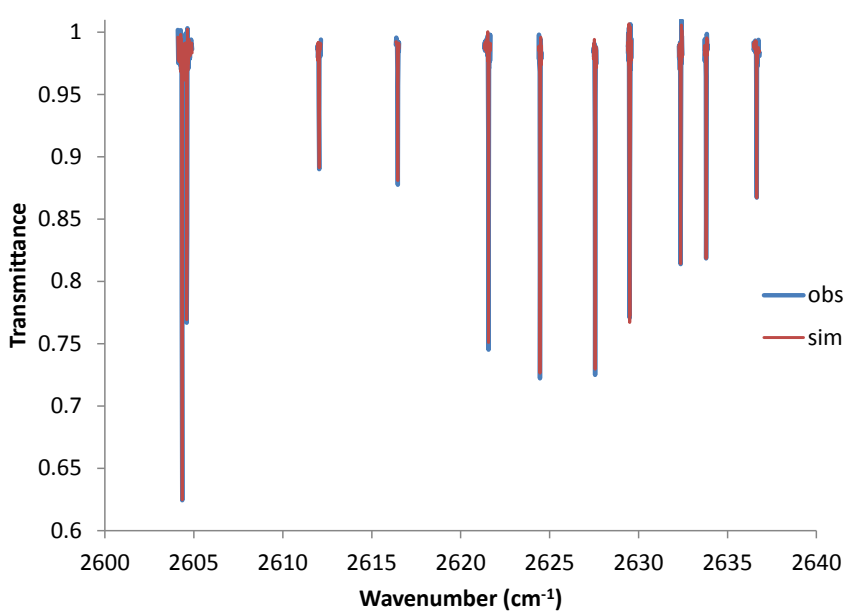

Figure 3d. Same as Fig. 3c but for $\mathrm{TH}=23.72 \mathrm{~km}$.

by Malathy Devi et al., 1984). The comparison with the more recent Teffo et al. (2003) measurements show a larger bias $(-6 \%)$ but reduced scatter (standard deviation of $0.8 \%$ ). The level of agreement for the $20002 \leftarrow 00001$ band is not sufficient to allow for a measurement of $\mathrm{CO}_{2}$ VMR with an overall uncertainty of 1-2\%. Unfortunately, the lines from the $v_{1}$ fundamental band are too strong to be used in the midtroposphere.

The optical thickness inside a microwindow contains contributions from lines that are up to $40 \mathrm{~cm}^{-1}$ outside the nearest microwindow edge (instead of $2.5 \mathrm{~cm}^{-1}$ ) used in the ACE v3.x retrieval algorithm. This is necessary because of contributions from the far wings of strong lines such as those belonging to the $v_{3}$ band of ${ }^{12} \mathrm{C}^{16} \mathrm{O}_{2}$, whose line shape is sub-Lorentzian. Instead, we use a Voigt profile for all bands and discuss the impact of this assumption in Sect. 2.3.

\subsubsection{Aerosol extinction}

If ignored, aerosol absorption can bias the retrieved THs by several hundred meters, rendering the simultaneously retrieved $\mathrm{CO}_{2}$ of little scientific value. Thus, aerosol transmittance is determined empirically and used to correct observed transmittances in the $\mathrm{N}_{2}$ CIA microwindows. This correction is necessary since aerosol extinction is not included in the forward model. The four spectral points (on the $0.02 \mathrm{~cm}^{-1}$ measurement grid) at the low frequency end of the $2637 \mathrm{~cm}^{-1}$ microwindow are used to determine the observed total transmittance (Fig. 4), thereby reducing the signal-tonoise ratio by a factor of $\sim 2$ compared to a single spectral point. Note that this microwindow covers the full TH range of the retrieval $(5-25 \mathrm{~km})$. Thus, it provides the information on the aerosol contribution over this same range. The total transmittance is assumed to be the product of the aerosol transmittance and combined transmittance of the various gases. The combined gas phase transmittance is determined using simulations with the ACE forward model (Boone et al., 2005) 


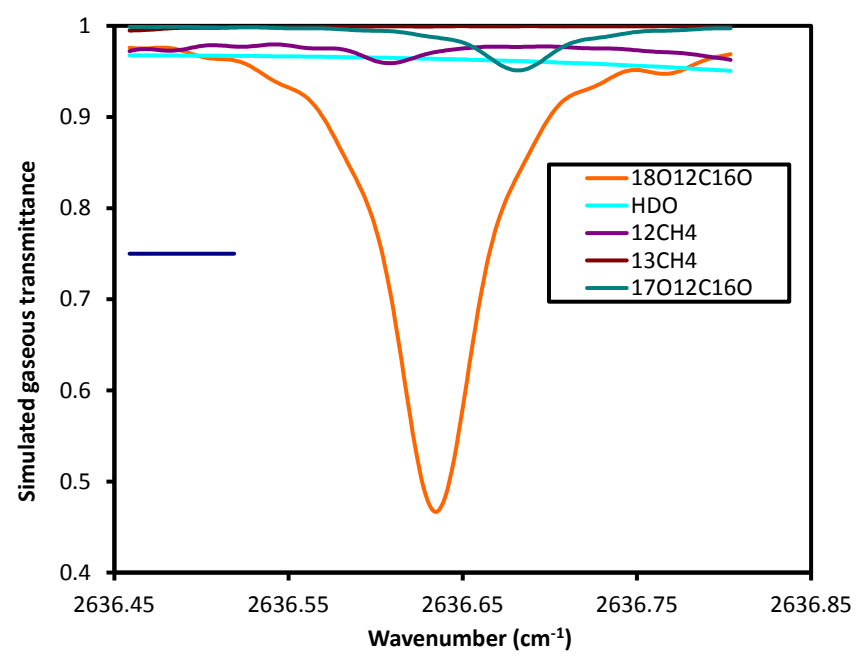

Figure 4. Transmittance contributions from various gaseous absorbers in the $2637 \mathrm{~cm}^{-1}$ microwindow at $\mathrm{TH}=6.3 \mathrm{~km}$. Other gases may provide trivial contributions. The portion of the microwindow used to determine aerosol transmittance is shown in dark blue. The corresponding transmittance value of 0.75 is meaningless (only the wavenumber range is relevant).

using the atmosphere and THs retrieved with the v3.x algorithm, except that the assumed $\mathrm{CO}_{2}$ VMR profile comes from a model which accounts for seasonal, altitudinal, and latitudinal variations (Boone et al., 2013). Dividing the observed total transmittance by the modelled gaseous transmittance yields the aerosol transmittance at $\sim 2637 \mathrm{~cm}^{-1}$. This is assumed to be equal to the aerosol transmittance in all of the $\mathrm{N}_{2}$ CIA microwindows (essentially $2430-2510 \mathrm{~cm}^{-1}$ ), which appears to be a reasonable assumption if the aerosol is assumed to be pure sulfuric acid or even a $64 \%$ by weight aqueous solution of $\mathrm{H}_{2} \mathrm{SO}_{4}$ (Nash et al., 2001), which is typical of stratospheric aerosol at $210 \mathrm{~K}$ (Clapp et al., 1997). Clouds are screened so the transmittance attributed to aerosol is unlikely to be due to water in solid or liquid form. Sulfate is the predominant aerosol in the stratosphere (Murphy et al., 2006) and also in the upper troposphere for cloud-free marine locations. Over land with strong convection, carbonaceous aerosols may dominate the aerosol burden in the upper troposphere (Froyd et al., 2009). We have not studied the absorption spectrum in the $2430-2640 \mathrm{~cm}^{-1}$ region by the latter aerosol type, but with the large number of classes of organics (Froyd et al., 2009), it is likely that some of them have spectrally dependent absorption in this wavenumber range.

\subsection{Error budget - ACE-FTS}

We begin the error budget description with a review of the available literature on error analysis for ACE-FTS $\mathrm{CO}_{2}$ retrieval. Rinsland et al. (2010) retrieved the partial column of $\mathrm{CO}_{2}$ in the $7-10 \mathrm{~km}$ range and determined the error contribution due to several important sources such as measurement noise, temperature profile, nitrogen continuum absorption coefficients, $\mathrm{CO}_{2}$ line intensities, aerosol absorption, $\mathrm{CO}_{2}$ isotopologue correction, ACE-FTS ILS (instrument line shape) function, and TH shift. Foucher et al. (2009, 2011) and Foucher (2009) also presented error budget information that considered measurement noise, parameter uncertainties ( $p$ and $T$ profiles and tangent height errors), uncertainties in the VMRs of other species as well as model and spectroscopic error. They considered the uncertainty in $\mathrm{TH}$ due to the uncertainty in $\mathrm{N}_{2}$ continuum absorption coefficient spectrum and modeling error due to uncertainty in the line shape in the far wings of $\mathrm{CO}_{2}$ and $\mathrm{N}_{2} \mathrm{O}$. Translating the tangent height error of $40 \mathrm{~m}$ to a $\mathrm{CO}_{2}$ error using $0.09 \mathrm{ppm} \mathrm{m}^{-1}$ (discussed below) gives a $3.6 \mathrm{ppm}$ error, which is comparable to the $\mathrm{CO}_{2}$ uncertainty due to other dominant errors such as measurement noise in $\mathrm{CO}_{2}$ microwindows and temperature error. In addition to these, we consider uncertainty due to

1. $\mathrm{N}_{2}$ CIA $T$-dependence in the $2430-2510 \mathrm{~cm}^{-1}$ range

2. $\mathrm{N}_{2}-\mathrm{O}_{2}$ CIA and its $T$-dependence

3. measurement noise in the aerosol transmittances inferred from the observed spectra at $2637 \mathrm{~cm}^{-1}$

4. spectral dependence of aerosol extinction in the 2430$2640 \mathrm{~cm}^{-1}$ region

5. unflagged cloud extinction

6. sub-Lorentzian line shape of the $\nu_{3}$ band of ${ }^{12} \mathrm{C}^{16} \mathrm{O}_{2}$

7. $\mathrm{CO}_{2}$ first guess profile (above and within the retrieval range)

8. pressure profile

9. wavelength calibration.

Before delving into each error source, we list sources which are not including in the current error budget. The uncertainty on the $\mathrm{N}_{2}$ VMR was not considered because it was expected to be trivial in the $5-25 \mathrm{~km}$ retrieval range. Rayleigh scattering was not considered since at a tangent height of $5.5 \mathrm{~km}$, the transmittance is 0.9984 at our highest wavenumber of $2637 \mathrm{~cm}^{-1}$. Another source of error which was neglected was $\mathrm{H}_{2} \mathrm{O}$ continuum absorption and it warrants further investigation. There is no bias if the $\mathrm{H}_{2} \mathrm{O}$ continuum transmittance at $\sim 2637 \mathrm{~cm}^{-1}$ is equal to its transmittance in the $\mathrm{N}_{2}$ CIA microwindows. For a worst-case scenario of a tropical atmosphere at $\mathrm{TH}=5.5 \mathrm{~km}$, the transmittance simulated with MODTRAN5.2 (Berk et al., 2005) is 0.9671 at $2637 \mathrm{~cm}^{-1}$ and maximizes at 0.9859 at $2507 \mathrm{~cm}^{-1}$ over the $\mathrm{N}_{2}$ CIA microwindow range $\left(2430-2507 \mathrm{~cm}^{-1}\right)$. Another source of error relates to the modelled gas phase transmittance at $\sim 2637 \mathrm{~cm}^{-1}$. Uncertainty in the transmittance at $\sim 2637 \mathrm{~cm}^{-1}$ due to each gaseous absorber can be implicitly taken into account in the error budget by propagating 
VMR and spectroscopic uncertainties through the retrieval. The uncertainty due to spectroscopic parameters of the interferers was not considered and should be considered in future work. Similarly, the uncertainties on spectroscopic parameters for the target gas $\left({ }^{18} \mathrm{O}^{12} \mathrm{C}^{16} \mathrm{O}\right)$ were also not considered, except for the line intensities, since it is expected to be the more important spectroscopic source of bias.

First, we address individual sources of error that affect retrieved $\mathrm{CO}_{2}$ exclusively via $\mathrm{TH}$ uncertainty which we group into error sources which relate to $\mathrm{N}_{2}$ CIA, aerosols, and finally, the sub-Lorentzian line shape of the $v_{3}$ band of ${ }^{12} \mathrm{C}^{16} \mathrm{O}_{2}$. Following these TH-related error sources, the remaining sources of error are then discussed in order of decreasing significance (error variance integrated over the retrieval range), although errors on assumed atmospheric state parameters are grouped together.

Biases in $\mathrm{TH}$ tend to lead to biases in $\mathrm{CO}_{2}$ of the same sign. Because pointing errors dominate over all other error sources when tangent heights offsets are $>70 \mathrm{~m}$, it is possible to empirically determine the $\mathrm{CO}_{2}$ sensitivity from a linear regression of TH offset versus $\mathrm{CO}_{2} \mathrm{VMR}$ using all altitudes. Each TH offset is determined by the difference between our retrieved TH and the corresponding ACE v3.x TH. In doing so over a large number of occultations, we obtain a $\mathrm{CO}_{2}$ sensitivity to tangent height offsets of $0.09 \mathrm{ppm} \mathrm{m}^{-1}$ from the slope term of the linear regression. Using the mean TH offset profile from Fig. 5 and this sensitivity, we can empirically translate the $\mathrm{TH}$ bias profile to a TH-related $\mathrm{CO}_{2}$ bias profile (Fig. 6). The TH precision, quantified by the standard deviation of the TH differences in Fig. 5, was not considered because we expect that, in general, ACE-FTS $\mathrm{CO}_{2}$ profiles need to be averaged for scientific purposes, particularly in the upper troposphere where individual $\mathrm{TH}$ precision may be $\sim 140 \mathrm{~m}$.

Next, we analyze the individual sources of TH-related error, which are mostly related to errors in model inputs. Perturbing the $\mathrm{N}_{2}$ absorption coefficient spectrum by a constant value of $0.9 \%$, which is the upper limit of the quadraturesum of the uncertainties stated by Lafferty et al. (1996) as discussed in Sect. 2.1, we find a bias that grows with decreasing $\mathrm{TH}$. We are not sure how to interpret this other than that the retrieved THs at the top of the retrieval range might have some sensitivity to $\mathrm{CO}_{2}$ absorption, particularly in the $\mathrm{N}_{2}$ CIA microwindows where slope and offset terms are not fitted. The resulting $\mathrm{CO}_{2}$ uncertainty increases from $\sim 2 \mathrm{ppm}$ to $\sim 4 \mathrm{ppm}$ from the top to the bottom of the retrieval range.

By switching between the $\mathrm{N}_{2}$ CIA $T$-dependence we obtained from the two best low-temperature $\mathrm{N}_{2}$ CIA laboratory measurements (Lafferty et al., 1996; Menoux et al., 1993) to wavenumbers as high as $2600 \mathrm{~cm}^{-1}$, we obtain an estimate of the related uncertainty (including random and systematic differences). The test was done on one occultation and the resulting TH offset profile was converted to a $\mathrm{CO}_{2}$ error by multiplying by the sensitivity of $0.09 \mathrm{ppm} \mathrm{m}^{-1}$. One of the largest errors occurs just below $18 \mathrm{~km}$ which

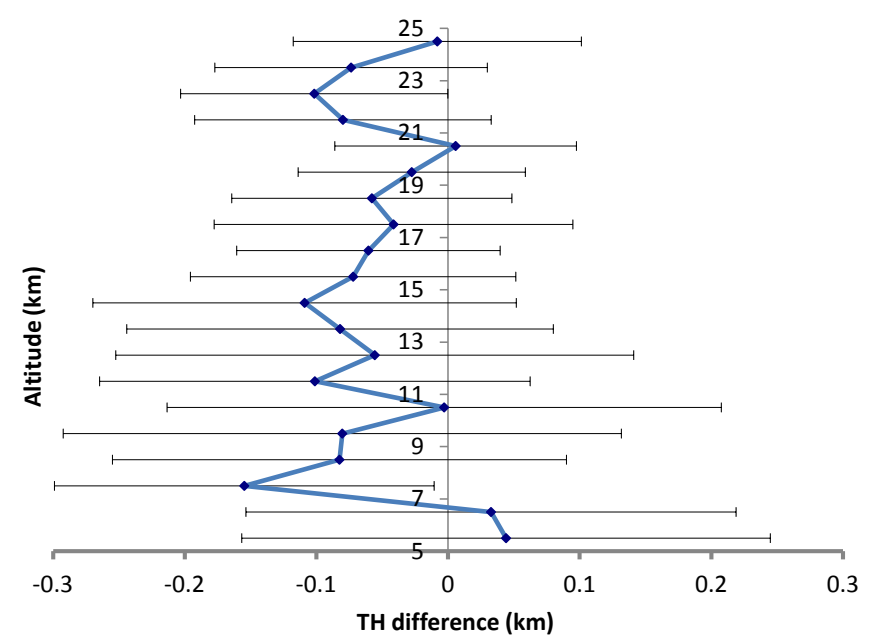

Figure 5. TH differences (this work minus ACE v3.x) averaged over 120 randomly selected occultations covering latitudes in the range $80^{\circ} \mathrm{N}$ to $68^{\circ} \mathrm{S}$ and spanning from January 2009 to January 2011. The error bars indicate the standard deviation of these differences. Note that each occultation does not provide data at all altitudes because of the TH sampling is typically $1-2 \mathrm{~km}$ but varying with beta angle and the lowest tangent height is often determined by the altitude of high, optically thick clouds.

is the upper altitude limit of a wide microwindow centered at $2492.1 \mathrm{~cm}^{-1}$ because of the differences that appear near $2485 \mathrm{~cm}^{-1}$ in Fig. 1. Errors of similar magnitude appear below $10 \mathrm{~km}$ again due to an oscillation in the temperature dependence derived from the noisier Menoux et al. (1993) measurements.

$\mathrm{N}_{2}-\mathrm{O}_{2}$ absorption coefficients in the region of the $\mathrm{N}_{2}$ CIA fundamental band are currently not included in HITRAN 2012 (Richard et al., 2012). Using the variation of $E_{\mathrm{O}_{2} / \mathrm{N}_{2}}^{\mathrm{N}_{2}}$ (Table 4 of Menoux et al., 1993) over six temperatures and perturbing the extreme temperature values by their uncertainties in opposite directions, we obtained a slightly different best fit that ultimately translates to biases of $<0.5 \mathrm{ppm}$ in retrieved $\mathrm{CO}_{2}$ at all altitudes.

Aerosol extinction is derived from the noisy measurements. The standard deviation $(\sigma)$ of the total observed transmittance for the four spectral points used for aerosol correction (see above) is a measure of the noise in the observed aerosol extinction. We propagated $+1 \sigma$ observational noise at each tangent height through the retrieval and found the $\mathrm{CO}_{2}$ sensitivity is $\pm 0.06 \mathrm{ppm}$.

We also considered the impact of a bias in the assumed spectral dependence of aerosol extinction in the 2430$2637 \mathrm{~cm}^{-1}$ region, which may occur if the chemical composition of the aerosols is not dominated by sulfuric acid (e.g., liquid water, ice water (Clapp et al., 1997), and organic aerosol). There are a variety of different aerosol types, particularly in the troposphere, but even the mass fraction of water and its physical state (ice or liquid) are 
important considerations because solid state absorptions tend to be broad and the proximity of the ice $\mathrm{O}-\mathrm{H}$ stretch near $\sim 3200 \mathrm{~cm}^{-1}$ to $2637 \mathrm{~cm}^{-1}$ could affect the slope of the aerosol extinction in the $2430-2637 \mathrm{~cm}^{-1}$ range (Clapp et al., 1997). The slope is currently assumed to be 0 (i.e., scaling factor of 1 between $2637 \mathrm{~cm}^{-1}$ and the $\mathrm{N}_{2}$ CIA microwindows) at all THs. To consider a different scaling factor, we first convert the "observed" aerosol transmittance (see above) to an optical depth, then multiply by the scaling factor and convert back to a transmittance to account for the exponential nature of Beer's law. The $\mathrm{CO}_{2}$ sensitivity is determined using the tangent height offsets multiplied by the $\mathrm{CO}_{2}$ sensitivity to $\mathrm{TH}$ error of $0.09 \mathrm{ppm} \mathrm{m}^{-1}$. We tested a scaling factor of 0.9 at all THs and found a maximum $\mathrm{CO}_{2}$ bias of $6 \mathrm{ppm}$ at the top of the retrieval range since $\mathrm{N}_{2}$ CIA decreases exponentially with height but aerosol extinction is observed to be generally linear with altitude in the stratosphere for volcanically unperturbed conditions (e.g., Sioris et al., 2010; Doeringer et al., 2012). Variability of the scaling factor with altitude was not considered.

Testing the effects of residual cloud contamination on the retrieval was challenging because the forward model does not simulate clouds. We made several attempts to identify occultations for which clouds were barely flagged in the hope of creating a subset of occultations with such borderline clouds to assess biases in $\mathrm{TH}$ and $\mathrm{CO}_{2}$ due to residual cloud contamination. Some of these clouds could include volcanic aerosol plumes due to the Sarychev eruption (Doeringer et al., 2012) which affected our period of study (2009-2011). In fact, two occultations were used for case studies in Doeringer et al. (2012), namely sunsets 31976 and 31868 , and each of these was found to have cloud tops at exactly the same tangent height as shown in that paper (e.g., their Fig. 4). This is true for both cloud products ( 970 and $2505.5 \mathrm{~cm}^{-1}$ ). The best test we devised was to take occultations with the following conditions:

1. Cloud tops occur at exactly the same altitude at 970 and $2505.5 \mathrm{~cm}^{-1}$.

2. Transmittance at cloud top is in the range of 0.82 to unity in cloud microwindow ( $a$ ) ( $\left.\operatorname{tran}_{\text {cld_top, } a}\right)$, where $a$ is 970 or $2505.5 \mathrm{~cm}^{-1}$.

3. Transmittance in the other microwindow at cloud top in

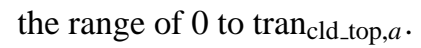

We collected 20 cases fulfilling the above conditions with the cloud top altitude being between 15 and $16 \mathrm{~km}$. The average transmittance was 0.84 and 0.85 at 970 and $2505 \mathrm{~cm}^{-1}$, respectively. We retrieved THs and $\mathrm{CO}_{2} \mathrm{VMR}$ for these cloudy cases and found the tangent heights were not biased in any detectable way relative to Fig. 5, particularly near $15 \mathrm{~km}$ (or below) where the bias would have been mostly likely to appear. The thin clouds are expected to affect the $\mathrm{CO}_{2}$ retrieval only via $\mathrm{TH}$ biases. Thus, the residual cloud

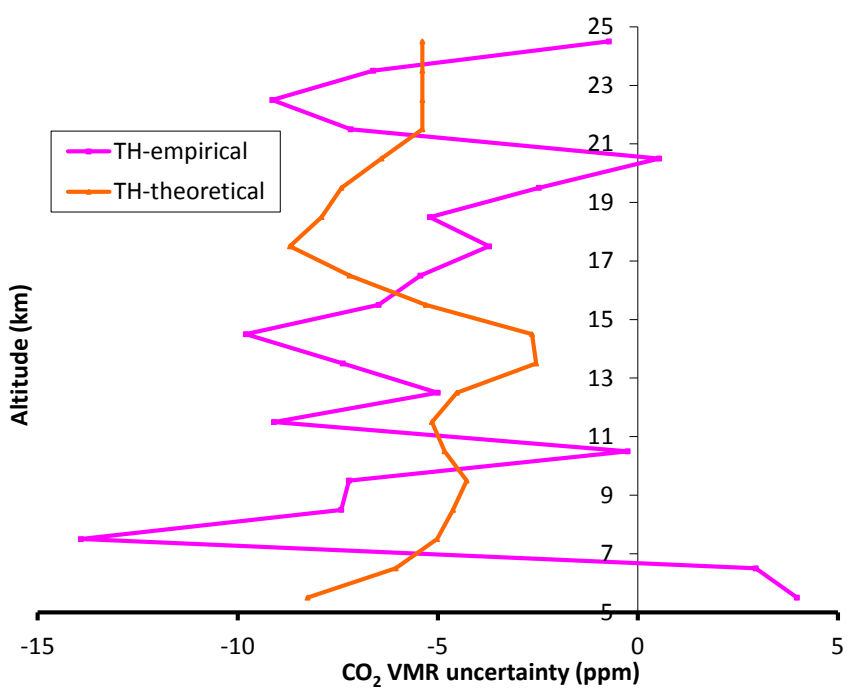

Figure 6. $\mathrm{CO}_{2}$ VMR uncertainty versus altitude due to tangent height uncertainty from two different methods. "TH-empirical" propagates the observed $\mathrm{TH}$ differences versus those retrieved using the ACE v3.x algorithm, and "TH-theoretical" includes all of the individual sources of TH-related error added in quadrature.

contamination is essentially zero given the current, stringent cloud flagging.

Finally, the sub-Lorentzian line shape in the $v_{3}$ band of ${ }^{12} \mathrm{C}^{16} \mathrm{O}_{2}$ was considered. Note that the lowest frequency in any $\mathrm{N}_{2}$ CIA microwindow is $2429.21 \mathrm{~cm}^{-1}$ and the range considered outside of the microwindow is $40 \mathrm{~cm}^{-1}$, so only 29 weaker lines of this $v_{3}$ band can contribute. We find the difference in retrieved THs and $\mathrm{CO}_{2} \mathrm{VMR}$ is trivial if the sub-Lorentzian line shape is selected given the $40 \mathrm{~cm}^{-1}$ range limitation.

In summary, the seven theoretical sources of error which affect $\mathrm{CO}_{2}$ via errors in retrieved $\mathrm{TH}$ are:

1. $\mathrm{N}_{2}$ CIA absorption coefficient

2. $\mathrm{N}_{2}$ CIA temperature $(T)$ dependence

3. $\mathrm{N}_{2}-\mathrm{O}_{2}$ CIA and its $T$-dependence

4. measurement noise in the aerosol transmittances

5. spectral dependence of aerosol extinction in the 2430$2640 \mathrm{~cm}^{-1}$ region

6. residual cloud extinction

7. sub-Lorentzian line shape.

The largest error source is the fifth one by far. Error sources $1,3,5$, and 6 result in $\mathrm{CO}_{2}$ biases whereas error sources 2 and 4 involve random error and result in $\mathrm{CO}_{2}$ retrieval error whose sign varies with altitude. Figure 6 shows errors for both empirical and theoretical approaches 
as negative in magnitude, since the former approach indicates that THs retrieved from the $\mathrm{N}_{2}$ CIA are biased low. The $\mathrm{CO}_{2}$ retrieval error averaged in the vertical direction (5$25 \mathrm{~km})$ is $-5.0 \pm 4.5 \mathrm{ppm}( \pm 1 \sigma)$ for the empirical method and $-5.6 \pm 1.7 \mathrm{ppm}$ for the quadrature-summed individual contributions, indicating that the two methods produce similar errors and neither method shows a strong difference between the troposphere and stratosphere $(>17 \mathrm{~km})$, whereas if the water vapor continuum (mentioned above) was a large source of error related to TH determination, there would be a major difference in the magnitude of errors from the empirical method across the hygropause ( $\sim 8-12 \mathrm{~km}$, depending on latitude). Note that the magnitude of the fifth source of error above was simply tested with an ad hoc and TH-independent scaling factor of 0.9 based on laboratory measurements of sulfuric acid absorption (Nash et al., 2001). Given that it is a major source of error among these individual TH-related terms, and the sufficient agreement between the empirically derived TH-related error and quadrature-summed theoretical error (within the altitudinal variability of the latter), the contribution from this error source has probably been reasonably estimated.

Biases in the $\mathrm{CO}_{2}$ line intensities will lead to opposite biases of the same relative magnitude in retrieved $\mathrm{CO}_{2}$ VMR. Each $\mathrm{CO}_{2}$ microwindow targets one strong line of ${ }^{18} \mathrm{O}^{12} \mathrm{C}^{16} \mathrm{O}$. To test the sensitivity of retrieved $\mathrm{CO}_{2}$ to uncertainties in the intensities of these targeted lines, the available measured line intensities from Malathy Devi et al. (1984) and Teffo et al. (2002) for $20002 \leftarrow 00001$ and the $v_{1}$ fundamental band, respectively, were used. Propagating this difference in $\mathrm{CO}_{2}$ line intensities (measured instead of modelled) results in a $5 \mathrm{ppm}$ negative bias in retrieved $\mathrm{CO}_{2} \mathrm{VMR}$ above $15 \mathrm{~km}$ and a $5-6 \mathrm{ppm}$ negative bias below $15 \mathrm{~km}$. The larger bias is expected below $15 \mathrm{~km}$ since the lines of the $20002 \leftarrow 00001$ band $\left(\sim 2600 \mathrm{~cm}^{-1}\right.$ region) are, on the whole, more biased relative to HITRAN 2012 than the lines of the fundamental band, and only the lines of the $20002 \leftarrow 00001$ band are used there.

To study the impact of the first guess $\mathrm{CO}_{2}$ profile, we did three independent tests and, at each altitude, retained the largest of the three perturbations at that altitude. The first test was to switch between the default of using the first guess from the a priori model (Keppel-Aleks et al., 2012) for Total Carbon Column Observing Network (TCCON, Wunch et al., 2011) retrievals, which will be used in ACE v4.0 retrievals (Boone et al., 2013), versus the $\mathrm{CO}_{2}$ first guess profile used in ACE v3.x retrievals. The TCCON a priori model captures the latitudinal, seasonal, and long-term variation of $\mathrm{CO}_{2}$ VMR. The second test involved increasing the ACE v4.0 $\mathrm{CO}_{2}$ profile by a factor of 1.0402 to account approximately for the atmospheric enrichment of ${ }^{18} \mathrm{O}^{12} \mathrm{C}^{16} \mathrm{O}$ due to fractionation (Wiegel et al., 2013). The third test used the VMR of ${ }^{17} \mathrm{O}^{12} \mathrm{C}^{16} \mathrm{O}$ within its retrieved range (55-96 km). These tests show a weak sensitivity of the least-squares inversion approach to the first guess of $\mathrm{CO}_{2}$ even at the top altitude, partly because the profile above the retrieval range is scaled by a retrieved constant (Boone et al., 2005).

For each interfering molecule, we performed similar tests to the $\mathrm{CO}_{2}$ first guess VMR tests described above. First, we positively perturb the assumed water vapor profile by its retrieval uncertainty $(<5 \%$ below $80 \mathrm{~km})$. This results in a $\sim 0.1 \mathrm{ppm}$ error in $\mathrm{CO}_{2}$ with no obvious altitude dependence. The second test relates to isotopic variation. In the default retrieval, we assume for each isotopologue of water vapor that its VMR is given by the VMR of the primary isotopologue (multiplied by the isotopic ratio of their natural abundances). There are no significant lines in any of our $\mathrm{CO}_{2}$ or $\mathrm{N}_{2} \mathrm{CIA}$ microwindows due to $\mathrm{H}_{2}{ }^{16} \mathrm{O}$. There are only two lines due to any water isotopologue which absorb strongly into the dry stratosphere. One belongs to HDO and the other is due to $\mathrm{H}_{2}{ }^{17} \mathrm{O}$, and both appear in the region of the ${ }^{18} \mathrm{O}^{12} \mathrm{C}^{16} \mathrm{O} v_{1}$ fundamental band. To test the impact of assuming the VMR based on $\mathrm{H}_{2}{ }^{16} \mathrm{O}$ and the standard isotopic ratio, which essentially is testing for the difference in profile shape due to atmospheric fractionation of a given isotopologue, we assume the ACE v3.x HDO VMR profile divided by its natural abundance. This is a worst-case scenario since atmospheric fractionation is stronger for HDO than $\mathrm{H}_{2}{ }^{17} \mathrm{O}$, and HDO is a minor absorber in the TH ranges of eight other microwindows whereas $\mathrm{H}_{2}{ }^{17} \mathrm{O}$ absorption is negligible except for the single strong line mentioned above. Note that we attempted to retrieve HDO simultaneously but the retrieved HDO profiles were not of sufficient quality in the stratosphere, likely because the one strong line is insufficient. A maximum $\mathrm{CO}_{2}$ sensitivity of $11 \mathrm{ppm}$ is found at the top of the retrieval range where the fractionation effect is strongest, decreasing rather steadily to $0.3 \mathrm{ppm}$ at $11 \mathrm{~km}$ when looking at an average of 10 difference profiles (to obtain a clearer $\mathrm{H}_{2} \mathrm{O}$ fractionation signal). Thus, the impact on $\mathrm{CO}_{2}$ of the atmospheric fractionation of water vapor is greater than that of the $\mathrm{H}_{2}{ }^{16} \mathrm{O}$ VMR retrieval uncertainty at all altitudes. The use of the HDO VMR profile shape leads to an improved $\mathrm{CO}_{2}$ profile shape and removes oscillations in individual $\mathrm{CO}_{2}$ profiles that dampen with decreasing altitude. This shall be used as the first guess for water vapor in future work.

$\mathrm{CH}_{4}$ affects both $\mathrm{N}_{2} \mathrm{CIA}$ and $\mathrm{CO}_{2}$ microwindows. For $\mathrm{CH}_{4}$, the ACE v3.x single profile retrieval uncertainty below $25 \mathrm{~km}$ is $\leq 3 \%$. Propagating this uncertainty profile (positive perturbation in the $5-75 \mathrm{~km}$ range) through the $\mathrm{TH}$ and $\mathrm{CO}_{2}$ retrieval algorithm leads to a consistent negative bias in retrieved $\mathrm{CO}_{2}$ of $\sim 0.2 \mathrm{ppm}$. According to ACE-FTS measurements, the isotopic fractionation between ${ }^{12} \mathrm{CH}_{4}$ and ${ }^{13} \mathrm{CH}_{4}$ is negligible (see also Rice et al., 2003) and the impact on retrieved $\mathrm{CO}_{2}$ is $\sim 0.04 \mathrm{ppm}$.

Finally, for $\mathrm{N}_{2} \mathrm{O}$, the ACE v3.x single profile retrieval uncertainty below $25 \mathrm{~km}$ is $\leq 3 \%$. Propagating this uncertainty profile (positive perturbation over the $\mathrm{N}_{2} \mathrm{O}$ retrieval range of 5-95 km) leads to a bias that changes sign, being negative above $11 \mathrm{~km}$ and positive below. The magnitude of the bias is always $\leq 0.7 \mathrm{ppm}$. The effect of fractionation of 
two non-primary isotopologues of $\mathrm{N}_{2} \mathrm{O}$ (listed in Sect. 2) is considered, assuming the differences in profile shape between isotopologues are real. The magnitude of the bias reaches $1.8 \mathrm{ppm}$ at $19.5 \mathrm{~km}$. The $\mathrm{CO}_{2} \mathrm{VMR}$ sensitivity to $\mathrm{N}_{2} \mathrm{O}$ changes appears to be via the microwindows targeting the ${ }^{18} \mathrm{O}^{12} \mathrm{C}^{16} \mathrm{O} 20002 \leftarrow 00001$ band (i.e., not indirectly via TH changes).

An error in temperature translates into an air number density error since the latter is calculated using the ideal gas law. $\mathrm{CO}_{2}$ bias due to air density bias is expected to dominate over the $\mathrm{CO}_{2}$ bias relating to the temperature dependence of the $\mathrm{CO}_{2}$ absorption, and the more temperature-sensitive $\mathrm{N}_{2}$ CIA, which has an indirect effect via the tangent heights. ACE-FTS retrieved temperatures (v2.2) have been validated by Sica et al. (2008) who found differences of $2 \mathrm{~K}$ in the stratosphere and upper troposphere. Schwartz et al. (2008) found ACE-FTS temperatures to be 5-7 K warmer between 0.1 and $0.02 \mathrm{hPa}$ (mesosphere) and $10 \mathrm{~K}$ warmer at $0.001 \mathrm{hPa}$ $(\sim 96 \mathrm{~km})$ relative to the Microwave Limb Sounder on Aura. Garcia-Comas et al. (2012) found MIPAS and ACE-FTS temperatures to agree within $2 \mathrm{~K}$ up to $55 \mathrm{~km}$ ( $3 \mathrm{~K}$ in polar winter). They also found agreement within $3 \mathrm{~K}$ in the lower mesosphere, $3-4 \mathrm{~K}$ at $70-75 \mathrm{~km}$, and within $5 \mathrm{~K}$ in the upper mesosphere. All of these preceding references for the quality of ACE-FTS temperatures used v2.2 data. In the only study using v3.x temperatures, Sheese et al. (2012) compared with OSIRIS and found $5 \mathrm{~K}$ differences in the 55 to $80 \mathrm{~km}$ range. Boone et al. (2013) illustrate and discuss the improvements to the temperatures retrieved from ACE-FTS between v2.2 and v3.x. Below $15 \mathrm{~km}$, temperatures are assumed from the analysis provided by the Canadian Meteorological Centre (CMC). According to Côté et al. (1998), these temperatures have biases of $2 \mathrm{~K}$ at pressures less than $500 \mathrm{hPa}$. As a worstcase scenario, we introduced a discontinuity in the temperature profile with a bias of opposite sign to the temperature bias (retrieved from ACE-FTS data) above $15 \mathrm{~km}$. Specifically, the following temperature bias profile was assumed:

$$
\begin{aligned}
& 5-15 \mathrm{~km}:-2 \mathrm{~K} \\
& 15-55 \mathrm{~km}:+2 \mathrm{~K} \\
& 55-70 \mathrm{~km}:+3 \mathrm{~K} \\
& 70-75 \mathrm{~km}:+4 \mathrm{~K} \\
& 75-80 \mathrm{~km}:+5 \mathrm{~K} \\
& 80-85 \mathrm{~km}:+6 \mathrm{~K} \\
& 85-100 \mathrm{~km}:+10 \mathrm{~K}
\end{aligned}
$$

Applying this assumed perturbation yields height retrieval errors of $-50 \mathrm{~m}$ at the highest altitudes $(18-22 \mathrm{~km})$, and positive retrieved height errors in the range of $10-40 \mathrm{~m}$ below $14 \mathrm{~km}$. The change of the sign of the height error relates to the opposing temperature bias (above and below $15 \mathrm{~km}$ ) as listed above. The $\mathrm{CO}_{2}$ retrieval bias due to this perturbed temperature profile is dominated by the air density perturbation particularly at the lowest temperatures (i.e., tropopause) where the relative change in air density of $\mathrm{a}+2 \mathrm{~K}$ perturbation will be greatest. The sensitivity of $\mathrm{CO}_{2}$ to temperature biases is reduced by the fact that there are canceling biases due to air density biases and TH-related biases (via $\mathrm{N}_{2}$ CIA). The $\mathrm{CO}_{2}$ retrieval bias reaches a local maximum in magnitude of $+1.2 \%$ at $16 \mathrm{~km}$ and this is the only altitude where the bias is significant relative to the retrieval uncertainty. There is a maximum at $5 \mathrm{~km}$ of $+1.4 \%$.

Errors in pressure can impact the $\mathrm{CO}_{2}$ retrieval algorithm because of pressure broadening of absorption lines. Below $15 \mathrm{~km}$, the pressure assumed in the $\mathrm{CO}_{2}$ retrieval comes from the CMC analysis (Côté et al., 1998). To obtain a reasonable pressure uncertainty, we took the geopotential height bias of the forecast at $100 \mathrm{hPa}(\sim 16 \mathrm{~km})$ of $25 \mathrm{~m}$ (Qaddouri and Lee, 2011 ) and converted this to a relative error of $\sim 0.16 \%$ and assumed that this corresponds to the relative pressure bias. Below this altitude, the relative geopotential height biases are actually smaller. We applied this $\sim 0.16 \%$ pressure bias to all altitudes up to $150 \mathrm{~km}$. The resulting impact on $\mathrm{CO}_{2} \mathrm{VMR}$ was rather random, with a standard deviation of $0.99 \mathrm{ppm}$ and height-averaged bias of $0.08 \mathrm{ppm}$.

To test the effect of the half-width of the instrument function, we independently changed each of the three parameters in the empirical expression used by Boone et al. (2013) for self-apodization by $2.86 \%$ based on worst-case spectral resolution variability determined at four wavenumbers along the ACE-FTS spectral range (Châteauneuf et al., 2005). $\mathrm{CO}_{2}$ VMR was sensitive mostly to the third parameter (biases of up to $1.3 \mathrm{ppm}$ ), with the sensitivity decreasing slightly from this upper limit at the top of the retrieval range where the width of the ILS exceeds the widths of the absorption lines to a relatively constant value of $1.1 \mathrm{ppm}$ below $13 \mathrm{~km}$ where the widths of the absorption lines can exceed the ILS width.

To test the sensitivity of $\mathrm{CO}_{2}$ to observation noise, we increased the noise in existing real ACE-FTS data without any TH-dependence by adding uniform noise, which is $1 / 454$ th of the signal. In combination with the existing real noise, which is $1 / 400$ th of the signal (Châteauneuf et al., 2005), we estimate that the final SNR would be reduced to approximately 300 . We find that changing the SNR from 400 to 300 made a difference of up to $1.6 \mathrm{ppm}$ in the retrieved $\mathrm{CO}_{2}$ with the greatest impact at the top of the profile, where the $\mathrm{CO}_{2}$ lines are less deep, and also below $7 \mathrm{~km}$, where absorption saturation leads to smaller transmittance signal changes per unit change in $\mathrm{CO}_{2}$ VMR.

Regarding the wavelength calibration, we tested the impact of changing the first guess of the wavelength calibration by $1 / 30$ th of the ACE-FTS spectral resolution. Larger perturbations are unrealistic given the accuracy of the wavelength calibration and the accuracy of the spectroscopic line parameters that are used. The retrieval is not expected to have much sensitivity to the first guess of the wavelength calibration because the wavelength calibration is determined again 
during the retrieval. The retrieved $\mathrm{CO}_{2} \mathrm{VMR}$ can change by $\pm 0.2 \mathrm{ppm}$.

With respect to the overall error budget, it was necessary to avoid double-counting certain sources of error. These sources of error are the empirically derived TH-related error and the observational noise in the $2637 \mathrm{~cm}^{-1}$ microwindow. For the former, we preferred the theoretically derived TH-related error profile because the empirically derived one is based on 129 occultations and the sample sizes are very small at the lowest THs (because sunset and sunrise occultations stop and start, respectively, at the top of optically thick clouds). An additional error contribution was added in quadrature into the overall error budget to account for the uncertainty of the relative isotopic fraction of ${ }^{18} \mathrm{O}^{12} \mathrm{C}^{16} \mathrm{O}$ caused by its atmospheric variability. ${ }^{18} \mathrm{O}^{12} \mathrm{C}^{16} \mathrm{O}$ is enriched in the troposphere by a relatively constant value of $\sim 4.1 \%$ (Kawagucci et al., 2008) relative to standard mean ocean water (SMOW), which is the standard used in HITRAN2012 for $\mathrm{CO}_{2}$ isotopic abundances. This factor varies with the abundance of $\mathrm{O}^{1} \mathrm{D}$ and thus, particularly in the stratosphere, it is a function of altitude, latitude, season and proximity to the polar vortex. In the stratosphere, using data from Kawagucci et al. (2008), we have taken this factor into account. We calculated a mean and standard deviation for this enrichment factor of $4.3 \pm 0.2 \%$. We have used this measure of variability in order to account for this uncertainty source when reporting total $\mathrm{CO}_{2}$ error based on ${ }^{18} \mathrm{O}^{12} \mathrm{C}^{16} \mathrm{O}$ measurements for all altitudes $>10 \mathrm{~km}$ and have assumed no related error in the troposphere. In the stratosphere, the uncertainty propagated to total $\mathrm{CO}_{2}$ is $0.8 \mathrm{ppm}$. The median absolute value of latitude for ACE-FTS $\mathrm{CO}_{2}$ data is $61^{\circ}$, where the tropopause is at $10 \mathrm{~km}$ in the Southern Hemisphere and $9 \mathrm{~km}$ in the Northern Hemisphere (SPARC, 1998).

The assumed water vapor profile is the dominant source of error at the top of the retrieval range. The contribution of aerosol extinction relative to $\mathrm{N}_{2}$ CIA is at a maximum in the lower stratosphere, near the Junge layer and this source of error dominates in the $18-21 \mathrm{~km}$ range. ${ }^{18} \mathrm{O}^{12} \mathrm{C}^{16} \mathrm{O}$ line intensity uncertainties dominate at all other altitudes, except at the temperature extremes, where the $T$-dependence of the $\mathrm{N}_{2}$ CIA becomes dominant. Figure 7 shows the total error ranges between 6 and $11 \mathrm{ppm}$. Many sources of error could be reduced with improved knowledge of forward model inputs.

\subsection{Error budget - CASS}

The proposed CASS mission (Melo et al., 2013) is under consideration by the Canadian Space Agency. The objectives of the mission are:

1. "climate and ozone balance monitoring" and

2. improved "knowledge of atmospheric processes driving climate and its changes".

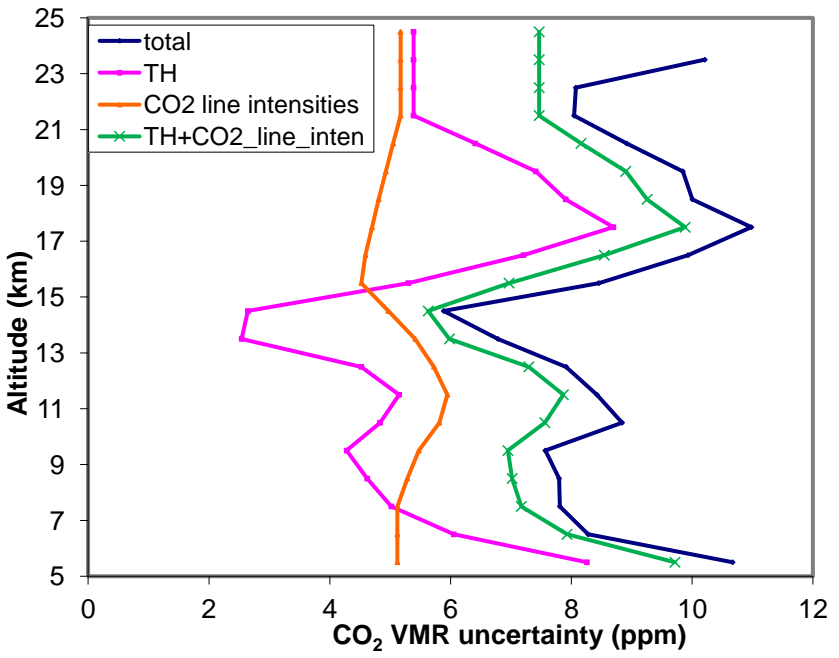

Figure 7. Overall error budget for ACE including TH-related contributions.

The CASS-FTS is very similar to the ACE-FTS, both consisting of Michelson interferometers, which use a pair of moving cube corner mirrors on a V-shaped scan arm. The optical path is folded in this design to give a double pass of the beams in each arm of the interferometer resulting in high spectral resolution for a compact size. The CASS-FTS has the same spectral sampling $\left(0.02 \mathrm{~cm}^{-1}\right)$ as the ACE-FTS and also uses the solar occultation technique to measure transmittance spectra in the $750-4400 \mathrm{~cm}^{-1}$ range. A tangent height range of 5 to $100 \mathrm{~km}$ is expected. The CASS orbit will likely have a lower inclination than ACE, offering better coverage of tropical and mid-latitudes. CASS-FTS is accompanied by solar imagers with the potential to independently provide improved pointing knowledge (Melo et al., 2013). Thus the error budget for CASS is different than the error budget for ACE with respect to uncertainties in $\mathrm{TH}$ and also in the temperature profile.

The CASS-FTS total $\mathrm{CO}_{2}$ uncertainty $(\sim 7-8 \mathrm{ppm})$ is not significantly lower than for ACE at most altitudes, but the magnitude depends strongly on the assumed tangent height uncertainty (Fig. 8). If the CASS imagers (or other methods) can achieve tangent height biases significantly better than $50 \mathrm{~m}$, this will yield smaller biases in the retrieved $\mathrm{CO}_{2}$ VMR profile. Furthermore, the TH precision for CASS is expected to be much better than the TH precision via the $\mathrm{N}_{2}$ CIA shown as horizontal bars in Fig. 5. Gordley et al. (2009) find a precision of \pm 0.02 arcsec is achievable (e.g., $0.27 \mathrm{~m}$ at $20 \mathrm{~km}$ ) with various bias sources which are significantly larger. This suggests that $\mathrm{N}_{2}$ CIA could be used to correct the TH bias but the spacing between successive tangent heights could be determined via refraction measurements using the imaged sun.

Temperature target accuracy for CASS-FTS is $2 \mathrm{~K}$ between $10-50 \mathrm{~km}$ and $4 \mathrm{~K}$ between $50-100 \mathrm{~km}$ and $5-10 \mathrm{~km}$. Propagation of this temperature bias leads to a $\mathrm{CO}_{2}$ bias of 


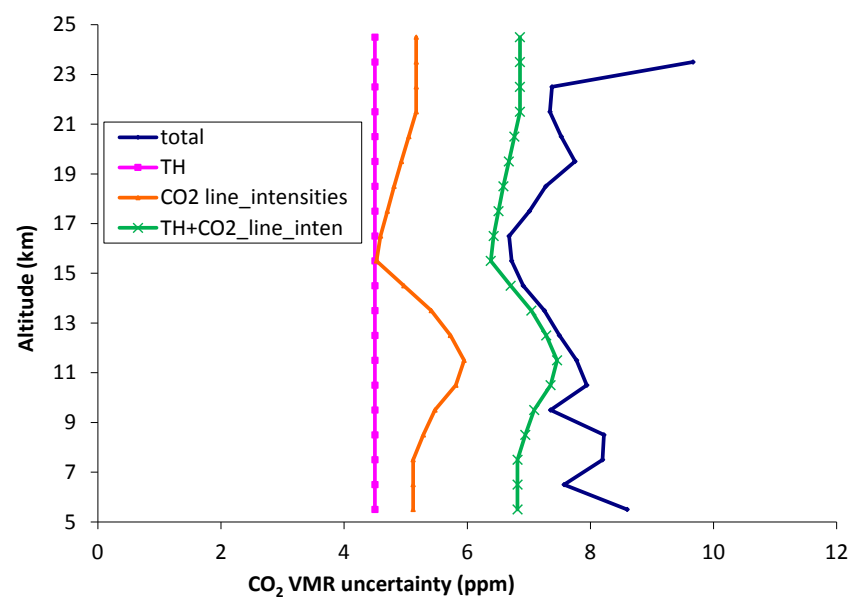

Figure 8. Total $\mathrm{CO}_{2}$ error budget for CASS-FTS, plus dominant individual terms. TH uncertainty is labelled "TH". The combination of $\mathrm{TH}$ and $\mathrm{CO}_{2}$ line intensity uncertainties is labelled "TH+CO2_line_inten" and serves to demonstrate that these two sources of error account for the majority of the total error.

$+1.7 \%$ at $5 \mathrm{~km}$, decreasing to $1 \%$ at $6 \mathrm{~km}$, and $<1 \%$ above $8 \mathrm{~km}$. Temperature is only a significant source of error at $9 \mathrm{~km}$ relative to retrieval uncertainties. The CASS-FTS temperature target accuracy is sufficient to achieve the $\mathrm{CO}_{2}$ target accuracy in the absence of other error sources.

\subsection{Post-processing data filters}

$\mathrm{CO}_{2}$ retrieved from ACE-FTS is generally reliable (see Sect. 3). However, on rare occasions the retrieved profile can be implausible. This may be a result of the aerosol extinction correction which may fail as transmittance at $2637 \mathrm{~cm}^{-1}$ approaches zero at low tangent heights. There may be other causes as well (e.g., missing or corrupt data). Thus from any of the results shown below, we exclude a small fraction of points with negative $\mathrm{CO}_{2}$ VMR. Also, we remove data points where the $\mathrm{CO}_{2}$ VMR uncertainty is reported as 0.00 or $>1000000 \mathrm{ppm}$ (i.e., uncertainty calculation failed). Finally, we removed points with VMR $>620 \mathrm{ppm}$ which filters clearly anomalous values (see below). We have been very conservative so as to not remove any high $\mathrm{CO}_{2}$ values that could result from rapid lofting of enhancements at the surface to heights of $>5 \mathrm{~km}$.

\subsection{Validation method}

Data from the following in situ sources are used: HIPPO (HIAPER Pole-to-Pole Observations) (Wofsy et al., 2011), CONTRAIL (Comprehensive Observation Network for Trace gases by Airline) (Machida et al., 2008), and CARIBIC (Civil Aircraft for the Regular Investigation of the atmosphere Based on an Instrument Container) (Schuck et al., 2009).
Multiple instruments on the five HIPPO measurement campaigns were used to measure $\mathrm{CO}_{2}$ (Wofsy et al., 2011); however, in this work we only use the $\mathrm{CO} 2 . \mathrm{X}$ data product. $\mathrm{CO} 2 . \mathrm{X}$ data is primarily made up of measurements from the quantum cascade laser spectrometer, with gap filling from the Observations of the Middle Stratosphere instrument (Daube et al., 2002). The HIPPO campaigns produced $\sim 150$ days of flight data, sampling 9 of 12 calendar months with good latitudinal and altitudinal coverage.

We used CONTRAIL measurements made by the continuous $\mathrm{CO}_{2}$ measuring equipment (CME) carried aboard commercial passenger aircraft. The CONTRAIL $\mathrm{CO}_{2}$ measurements used in this work were made with a non-dispersive infrared (NDIR) gas analyzer (Licor 840).

For CARIBIC, air samples are collected from commercial aircraft flights using an automated system. The samples obtained are analyzed in a laboratory using a gas chromatograph equipped with a flame ionization detector, for which $\mathrm{CO}_{2}$ is converted to $\mathrm{CH}_{4}$ using a nickel catalyst prior to analysis (Schuck et al., 2009).

ACE-FTS single profile measurements are compared with monthly $10^{\circ}$ zonal means of in situ data in $1 \mathrm{~km}$ vertical increments. Validation opportunities cover the 5.075$13.999 \mathrm{~km}$ range of ACE altitudes and years 2009 to 2011 . If more than one correlative instrument provides a validation opportunity in the same year and month, latitude band, and height interval, then we avoid duplication by selecting only data from one correlative instrument, in the following priority sequence: HIPPO, CONTRAIL, and CARIBIC. The difference between these three instruments at ACE-FTS $\mathrm{CO}_{2}$ geolocations is $<1.0 \mathrm{ppm}$. CARIBIC appears to have slightly more variability than the other in situ data sets. HIPPO is preferred because of its latitudinal and vertical coverage. The ACE-FTS retrieved VMR of ${ }^{18} \mathrm{O}^{12} \mathrm{C}^{16} \mathrm{O}$ is converted to total $\mathrm{CO}_{2}$ (i.e., all isotopologues) by dividing by its SMOW isotopic abundance fraction. In the troposphere $(z \leq 10 \mathrm{~km})$, we also divide by 1.0402 (Wiegel et al., 2013) which accounts for the difference between the SMOW standard and the more appropriate Pee Dee Belemnite (PDB) standard. For the stratosphere $(z>10 \mathrm{~km})$, we divide the $\mathrm{ACE}$ total $\mathrm{CO}_{2}$ VMR by 1.04314 instead to account for a minor contribution from atmospheric fractionation in the stratosphere. Post-processing data filters (see Sect. 2.5) are applied.

\section{Results and discussion}

\subsection{Retrieved tangent heights}

Using the improved temperature dependence of the $\mathrm{N}_{2}$ CIA and accounting for aerosol extinction in the $\mathrm{N}_{2}$ CIA microwindows, we found improved pointing accuracy relative to using the temperature dependence of Foucher (2009) by comparison with the ACE-FTS v3.x tangent heights. Using 


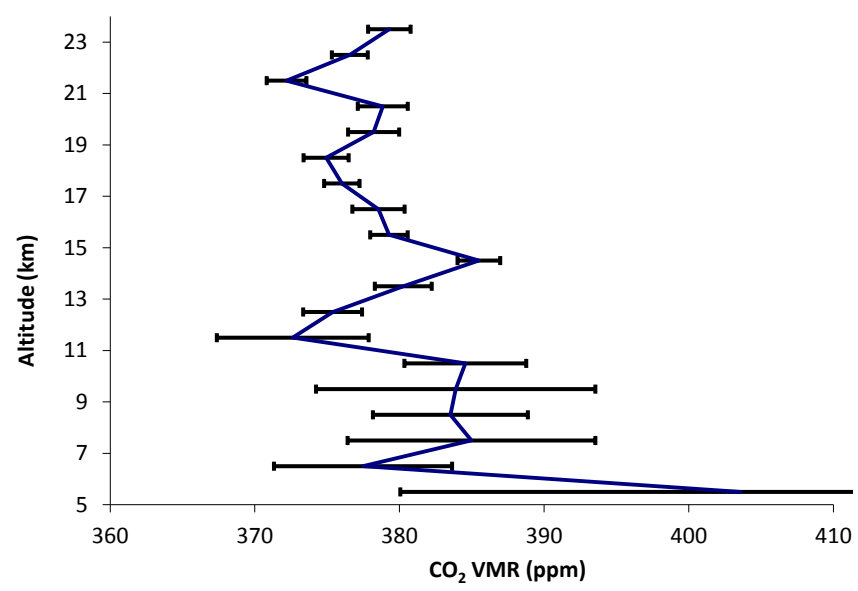

Figure 9. Three-year (2009-2011) global median of cloud-free $\mathrm{CO}_{2} \mathrm{VMR}$ in the 5-24 km range (869 profiles). The error bar shows the standard error at each $1 \mathrm{~km}$ altitude bin (centered at 5.5 to $23.5 \mathrm{~km})$.

the $\mathrm{N}_{2}$ CIA temperature dependence of Foucher (2009) leads to a low bias of $200 \mathrm{~m}$ relative to ACE-FTS v3.x tangent heights. The impact of neglecting the aerosol extinction in the $\mathrm{N}_{2}$ CIA microwindows introduces altitude-dependent $\mathrm{TH}$ offsets that become very apparent if the TH retrieval spans a sufficient range (5-25 km). This is discussed in Sect. 4.

Boone et al. (2005) report a residual $\sim+100 \mathrm{~m}$ difference in THs retrieved independently using ${ }^{18} \mathrm{O}^{12} \mathrm{C}^{16} \mathrm{O}$ and ${ }^{16} \mathrm{O}^{12} \mathrm{C}^{16} \mathrm{O}$ microwindows with the ACE v2.2 retrieval software, after correcting for an apparent high bias of $3.5 \%$ in the VMR of the rarer isotopologue. This correction factor was increased to $+4.3 \%$, which is a more representative value for the isotopic enrichment of ${ }^{18} \mathrm{O}^{12} \mathrm{C}^{16} \mathrm{O}$ in the stratosphere (Wiegel et al., 2013; Kawagucci et al., 2008) for ACE v3.x retrievals. Thus, ACE v3.x THs would be expected to have this high bias reduced to $+43 \mathrm{~m}$ assuming the latter correcting factor. Thus, the $-61 \mathrm{~m}$ bias versus ACE v3.x THs shown in Fig. 5 is reduced to $-18 \mathrm{~m}$ when the ACEv3.x TH high bias due to $\mathrm{CO}_{2}$ isotopic inconsistencies is considered.

Using the HITRAN 2012 line list for the retrieval of THs using the ACE v3.x software leads to a decrease in THs of $62 \pm 8 \mathrm{~m}$ in the $15-25 \mathrm{~km}$ range relative to the use of the default line list which is an updated version of HITRAN 2004. Similarly, below $15 \mathrm{~km}$ where ${ }^{18} \mathrm{O}^{12} \mathrm{C}^{16} \mathrm{O}$ lines are exclusively used for ACE v3.x TH retrieval (Boone et al., 2013), a larger TH decrease of $118 \pm 45 \mathrm{~m}$ is observed.

Finally, the ACE v3.x THs are biased low because of the low-biased $\mathrm{CO}_{2}$ VMR profile due to the underestimated growth rate of $1.50155 \mathrm{ppm}_{\text {year }}{ }^{-1}$ of $\mathrm{CO}_{2}$ (Boone et al., 2005). To study this effect, we have used the TCCON a priori $\mathrm{CO}_{2}$. Foucher et al. (2009) noted that the seasonal cycle of $\mathrm{CO}_{2}$ in the troposphere could lead to seasonally varying biases in the mid-tropospheric THs. By replacing the default $\mathrm{CO}_{2}$ VMR profile with profiles from the TCCON a priori

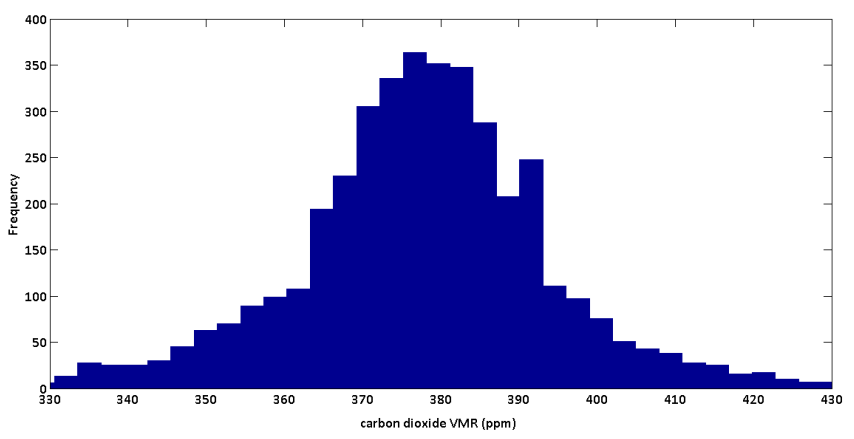

Figure 10. Histogram of retrieved cloud-free $\mathrm{CO}_{2}$ VMR at all altitudes (5-25 km), globally, in the 2009-2011 time frame. Outside of this range, the frequency distribution tends to be random (no resemblance to a Gaussian).

$\mathrm{CO}_{2}$ for the Northern Hemisphere mid-latitude in April and October, we find that the THs above $10 \mathrm{~km}$ are not sensitive to the seasonal cycle of $\mathrm{CO}_{2}$, consistent with Foucher et al. (2009), but exhibit sensitivity to the low bias in assumed $\mathrm{CO}_{2} \mathrm{VMR}$ due to the underestimated growth rate. The bias in THs due to assumed $\mathrm{CO}_{2}$ is $+40 \pm 20 \mathrm{~m}$ at $25 \mathrm{~km}$, partly due to the assumption of a constant VMR profile in the stratosphere $(20-60 \mathrm{~km})$, whereas the TCCON a priori profiles shows a $4.5 \mathrm{ppmv}$ increase from $60 \mathrm{~km}$ down to $20 \mathrm{~km}$. This bias in TH grows steadily to $\sim+110 \mathrm{~m}$ at the tropopause $(10 \mathrm{~km})$. In summary, two changes have been included in the ACE v3.x TH retrieval to make the resulting THs more accurate:

1. spectroscopic update and

2. assumed $\mathrm{CO}_{2}$ VMR profile.

The two changes have opposite effects that are of the same magnitude both above and below $15 \mathrm{~km}$. Thus the ACE v3.x tangent heights are essentially unchanged within $50 \mathrm{~m}$ (for altitude above $7 \mathrm{~km}$ ) when both of these effects are taken into account simultaneously.

\subsection{Validation of $\mathrm{CO}_{2}$ profiles versus latitude with in situ data}

Figure 9 shows a three year (2009-2011) $\mathrm{CO}_{2}$ median profile from cloud-free data. Figure 10 shows a histogram of the cloud-free data points using all retrieval altitudes, justifying our use of $620 \mathrm{ppm}$ as a cut-off (see Sect. 2.5). We validate individual data points by latitude and altitude with in situ data from airborne sensors. Using only clear-sky data, certain latitude regions provided few validation opportunities, especially in the troposphere. Therefore, we attempted to expand the number and spatial coverage of validation opportunities by including a subset of data which was flagged as cloudy at $2505.5 \mathrm{~cm}^{-1}$ but not at $970 \mathrm{~cm}^{-1}$. These are not tropospheric clouds, but rather polar, lower stratospheric aerosols 


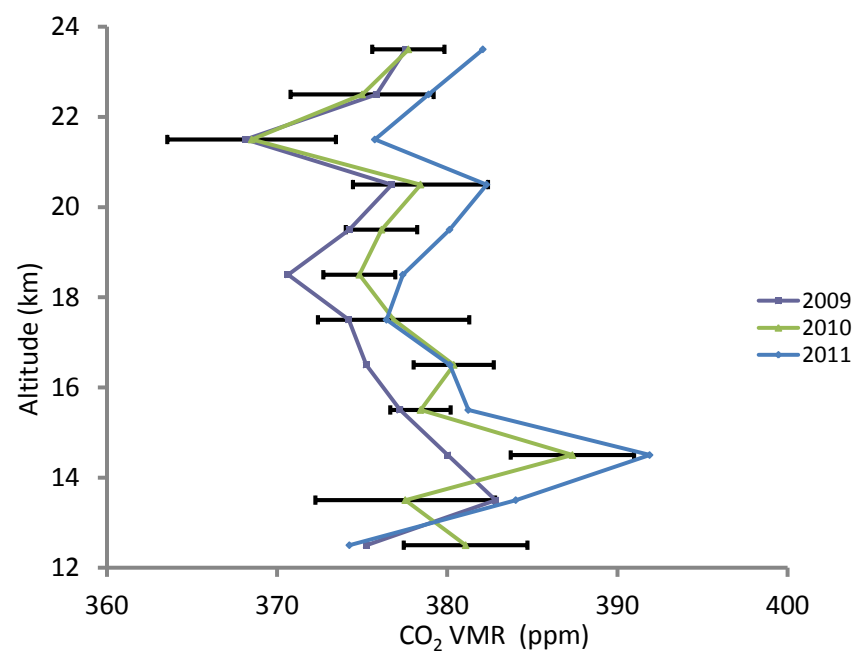

Figure 11. Annual growth of $\mathrm{CO}_{2}$ versus altitude using yearly medians from the cloud-free data set. Error bars show the standard error for 2010. Between 12 and $25 \mathrm{~km}$ and over all latitudes, the growth rate is 2.1 and $2.8 \mathrm{ppm}_{\text {year }}{ }^{-1}$, or $2.47 \pm 0.67 \mathrm{ppm}_{\text {year }}{ }^{-1}$ averaged over 2009-2011.

that occur in all seasons. Most of these aerosols likely include water-ice which absorbs in the $2100-3600 \mathrm{~cm}^{-1}$ region (Clapp et al., 1997) and forms at temperatures below $210 \mathrm{~K}$ (depending on mass fraction of sulfate relative to water-ice). Based on the $2505.5 \mathrm{~cm}^{-1}$ cloud flag, these aerosols are observed to exist in a narrow layer between 13 and $15 \mathrm{~km}$. We retrieved $\mathrm{CO}_{2} \mathrm{VMR}$ from all occultations belonging to this subset of data using v3.0 inputs for 2009 and up to September 2010 and v3.5 inputs after September 2010 until the end of 2011. This was necessary since v3.0 data is not valid beyond September 2010 (Boone et al., 2013). The retrieved $\mathrm{CO}_{2}$ profiles show a high bias of $8 \mathrm{ppm}$ at 13.5 and $7 \mathrm{ppm}$ at $14.5 \mathrm{~km}$, and no significant impact on this 21 -month median profile at all other altitudes (not shown). We validate this "cloudy" data set as well, which greatly improves our ability to detect latitudinal biases at lower altitudes.

Longitudinal variations are not validated. The annual growth (Fig. 11) validates the stability of the retrieved $\mathrm{CO}_{2}$ versus time. Furthermore, it demonstrates that small increases of 2-3 ppm year ${ }^{-1}$ are detectable when averaging vertically over the lower stratosphere.

The global median bias including all latitudes and altitudes is $-1.7 \pm 0.4 \mathrm{ppm}$ ( \pm standard error, SE). Figure 12 shows that between 7 and $12 \mathrm{~km}$, the only significant biases occur at $8 \mathrm{~km}(6.2 \pm 2.3 \mathrm{ppm})$ and negative biases of $2.3 \pm 0.5 \mathrm{ppm}$ over the 9-12 km range. At 5-6 km, there are too few coincidences $(N \leq 13)$ to determine whether the bias is statistically significant. The negative bias in the $9-12 \mathrm{~km}$ region is driven by known negative $\mathrm{CO}_{2}$ bias of $5 \pm 3 \mathrm{ppm}$ due to tangent height offsets (Fig. 6). At $13 \mathrm{~km}$, the positive bias of $7 \pm 1 \mathrm{ppm}( \pm \mathrm{SE})$ is due to aerosol-related biases in the

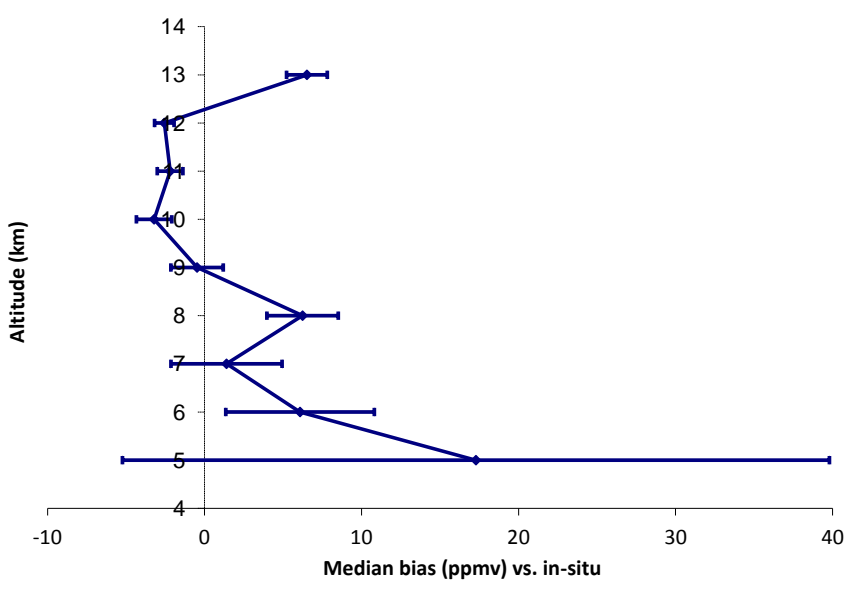

Figure 12. Validation results by height, combining all latitudes. The error bar is the standard error of the bias. Sample sizes $(N)$ are $>20$ in the $7-13 \mathrm{~km}$ range.

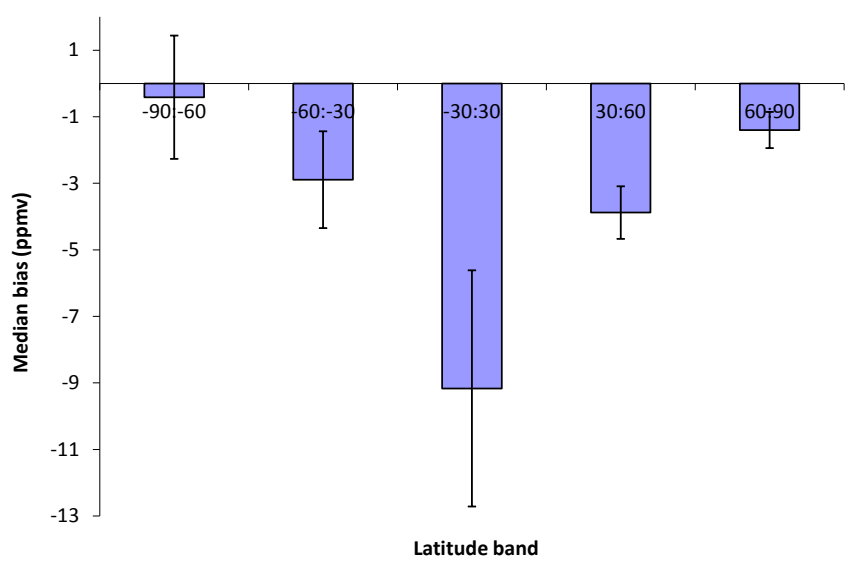

Figure 13. Validation by latitude band combining all heights below $13 \mathrm{~km}$. The error bar is the standard error of the ensemble of pairwise biases.

cloudy cases. The cause of the positive bias at $8 \mathrm{~km}$ is not known, but the bias is $<2 \%$ of $\mathrm{CO}_{2}$.

Figure 13 shows the validation by latitude band for ACEFTS data points below $13.0 \mathrm{~km}$. All latitude bands also show a negative bias of $\sim 5 \pm 5 \mathrm{ppm}$. Again, the sign and magnitude of the negative bias at most latitudes is expected.

We focus on the latitude bands with the most validation opportunities (Fig. 13), namely high and mid-latitudes, in order to examine the altitude dependence of any latitudinal bias. At southern mid-latitudes, the validation indicates significant negative biases only at 10 to $12 \mathrm{~km}$ of $5 \pm 3(N=28)$, $4 \pm 2 \mathrm{ppm}(N=40)$, and $6 \pm 4 \mathrm{ppm}(N=32)$, respectively (Fig. 14). The sign and magnitude are expected based on tangent height bias. At $13 \mathrm{~km}$, the sign and magnitude of the positive bias of $3 \pm 3 \mathrm{ppm}$ is expected from aerosol-related biases in the cloudy subset $(\sim 8.5 \mathrm{ppm})$, offset by a negative 


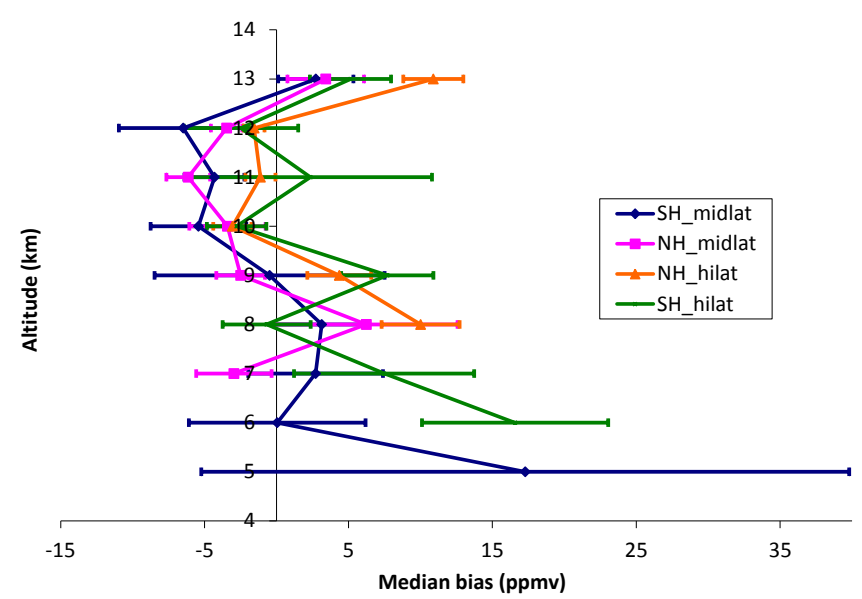

Figure 14. Same as Fig. 12 but only for high and mid-latitude regions.

offset of 5 ppm from low-biased THs. At all other altitudes, the biases are statistically insignificant.

For Northern Hemisphere mid-latitudes, samples sizes are small $(N<20)$ below $9 \mathrm{~km}$. The bias is consistent with southern mid-latitudes in the $9-12 \mathrm{~km}$ range. At $13 \mathrm{~km}$, given that the validation opportunities are almost entirely for cloudy cases, the $+8.5 \mathrm{ppm}$ expected bias due to aerosols (discussed above) is added on a negative bias of $\sim 5 \mathrm{ppm}$ from tangent heights. Thus a positive bias of $3.5 \mathrm{ppm}$ is expected, which agrees with the observed $3.4 \pm 2.7 \mathrm{ppm}$ bias $( \pm \mathrm{SE})$.

For northern high latitudes, the validation sample size is small $(N \leq 12)$ below $9 \mathrm{~km}$. The sample sizes are adequate $(N \geq 20)$ in the $9-12 \mathrm{~km}$ range. Between 10 and $12 \mathrm{~km}$, a negative bias of $1 \pm 1 \mathrm{ppm}$ is observed, similar to midlatitudes, and at $13 \mathrm{~km}$, a positive bias of $11 \pm 2 \mathrm{ppm}$ is found, slightly larger than other latitude bands and caused by cloudy points. The high bias $(\sim 1 \%)$ at northern high latitudes at $9 \mathrm{~km}$ largely determines the global bias at $8-9 \mathrm{~km}$ (Fig. 12). As mentioned, its cause is not understood.

At southern high latitudes, the sample size is sufficient only at $12-13 \mathrm{~km}$. At $12 \mathrm{~km}$, the bias is not significant, whereas at $13 \mathrm{~km}$, a positive bias of $5 \pm 3 \mathrm{ppm}$ is found, similar to other latitudes, and almost entirely due to the positive bias relating to lower stratospheric aerosols.

\section{Conclusion and future work}

There are four major advances in this work over the previous work (e.g., Foucher et al., 2011 and references therein):

1. the transmittance due to sulfate aerosol is considered

2. significantly improved temperature-dependence of $\mathrm{N}_{2}$ CIA
3. addition of several narrow $\mathrm{N}_{2}$ CIA microwindows to improve retrieval of the $\mathrm{TH}$ vector

4. no use of a priori information for regularization of the retrieved profile.

If sulfate aerosol transmittance is neglected, the TH offsets relative to ACE v3.x have a gradient versus $\mathrm{TH}$ of several hundred meters because the contribution of aerosol absorption relative to $\mathrm{N}_{2}$ CIA grows with increasing TH. $\mathrm{N}_{2}$ CIA decreases quadratically with decreasing air density (i.e., increasing $\mathrm{TH}$ ) due to the bimolecular nature of the absorption whereas aerosol absorption is expected to decrease more linearly as aerosol extinction is proportional to air density for background cases. Foucher (2009) found such a TH offset gradient as well and used averaged vertical profiles of $\mathrm{TH}$ offsets to correct for their neglect of aerosol absorption. Their method is susceptible to aerosol variability which can be significant given recent volcanic activity (Sioris et al., 2010; Doeringer et al., 2011).

A consistent spectrum of the temperature-dependence coefficient for the $\mathrm{N}_{2}$ CIA is found between the measurements of Lafferty et al. (1996) and Menoux et al. (1993). The use of Hartmann's temperature-dependence led to THs that were offset by $>1 \mathrm{~km}$ from those obtained using the ACE v3.x retrieval. This necessitated the re-analysis of Lafferty et al. (1996) data to obtain a much improved temperature dependence spectrum (Foucher, 2009). Using Foucher's temperature dependence, we obtain a mean TH offset of $-200 \mathrm{~m}$ relative to ACE v3.x with no significant vertical gradient, whereas using the temperature dependence determined here, the TH offset is further reduced, typically to less than $100 \mathrm{~m}$.

The retrievals shown in Foucher et al. $(2009,2011)$ show a strong dependence on the a priori profiles particularly above $20 \mathrm{~km}$, which, in turn, leads to reduced variability in retrieved $\mathrm{CO}_{2}$ compared with our work. Specifically, if we use their small set of $\mathrm{N}_{2}$ CIA microwindows, we also find a kink in the retrieved $\mathrm{CO}_{2}$ profile near $16 \mathrm{~km}$ (Foucher et al., 2011) which we find to be related to inconsistencies between $\mathrm{N}_{2}$ CIA microwindows. This kink is damped in their retrieval by constraining $\mathrm{CO}_{2}$ to the a priori profiles. We find a much larger anomaly appears at the same altitude in our retrieved $\mathrm{CO}_{2}$ profiles and the vertical profile of TH offsets (averaged over a large number of occultations). Using an improved and more extensive set of $\mathrm{N}_{2}$ CIA microwindows (Table 1), significant kinks are largely reduced.

Future endeavors should include the simultaneous retrieval of the $B_{0}$ and $\beta_{0}$ parameters from the measurements of Lafferty et al. (1996). Ideally the simultaneous retrieval of these spectral quantities could be performed on a finer grid than $5 \mathrm{~cm}^{-1}$. Then, the $\mathrm{CO}_{2}$ retrieval could be repeated using $\mathrm{N}_{2}$ CIA parameters on a finer grid. This may capture some of the weak, fine structure in the $\mathrm{N}_{2}$ CIA that has been the subject of much investigation (e.g., Lafferty et al., 1996; Moreau, 1999). 

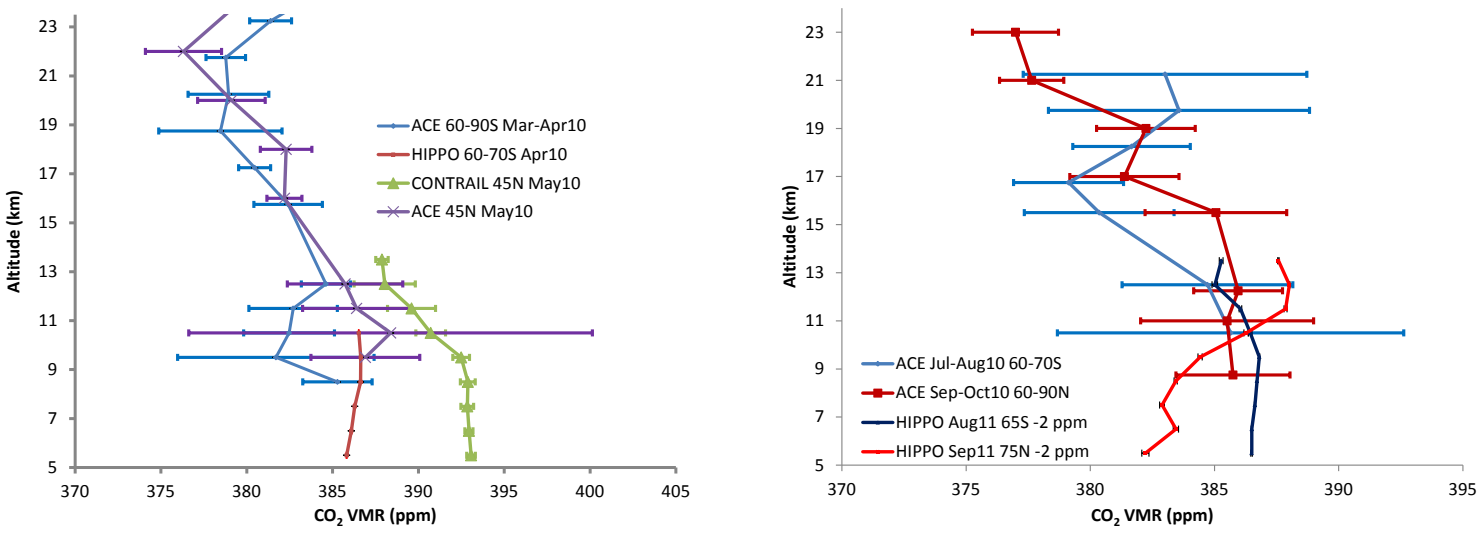

Figure 15. On the left - latitudinal gradient in $\mathrm{CO}_{2}$ VMR observed in boreal spring using satellite-based observations (ACE-FTS) and in in situ data (HIPPO and CONTRAIL). All measurements are from the year 2010. The $45^{\circ} \mathrm{N}$ band comprises measurements from $30-60^{\circ} \mathrm{N}$ for both ACE-FTS and CONTRAIL. Medians are shown for ACE-FTS to reduce sensitivity to outliers while averages are shown for HIPPO and the error bars are the standard errors for both instruments. For CONTRAIL, we plot the average three sub-bands (30-40, 40-50, and $50-60^{\circ} \mathrm{N}$ ), and each error bar represents the standard error of the three sub-band averages at that altitude. ACE-FTS data points between 13.0 and $15.0 \mathrm{~km}$ are excluded due to aerosol extinction (affects THs). Vertical bins of 1.5 and $2 \mathrm{~km}$ are used above $15.0 \mathrm{~km}$ to improve samples sizes per bin, particularly above $19.0 \mathrm{~km}$ for the ACE-FTS profiles of March to April $60-90^{\circ} \mathrm{S}$ and May $45^{\circ} \mathrm{N}$, respectively. On the right - same as left panel but for boreal summer. HIPPO measurements are from the year 2011, so we subtract 2 ppm to account for the annual growth.

Microwindows could be added to retrieve non-primary isotopologues of interfering species simultaneously and accurately. There are $\sim 500000$ available $\mathrm{CO}_{2}$ lines in HITRAN 2012. Additional microwindows for $\mathrm{CO}_{2}$ should be sought to improve detection in the upper troposphere where $\mathrm{CO}_{2}$ retrieval uncertainties grow exponentially. For example, the retrieval uncertainty, which is a statistical output of the leastsquares retrieval algorithm, can be as small as $1.0 \mathrm{ppm}$ at $10 \mathrm{~km}$ (Antarctic stratosphere), whereas at 5 and $6 \mathrm{~km}$, the minimum statistical uncertainty in the cloud-free data set grows to 11 and 5 ppm, respectively.

Next, we discuss whether the ACE-FTS $\mathrm{CO}_{2}$ data set presented here is sufficiently precise to detect natural variability on monthly and annual time scales, a large latitudinal scale, or vertically within a $5 \mathrm{~km}$ range $(7-12 \mathrm{~km})$ in the upper troposphere and lower stratosphere. Detecting $\mathrm{CO}_{2}$ variations over shorter spatial and temporal scales becomes more challenging. The small-scale variability is determined by looking at the variability about the monthly mean, calculated in $10^{\circ}$ latitude bins and $1 \mathrm{~km}$ vertical increments. Using the HIPPO data set, natural small-scale variability reaches a maximum of $4.3 \mathrm{ppm}$ (standard deviation, $N=64$ ) at $5.5 \mathrm{~km}$ at $85^{\circ} \mathrm{N}$ in July 2011. However, monthly-scale temporal variability can be determined by looking at variations between consecutive months (for the same altitude and latitude). At an annual time scale, time-dependent measurement biases (i.e., drifts) are much smaller than the annual increase in $\mathrm{CO}_{2}$. Natural yearto-year variations are small, on the order of $2.5 \mathrm{ppm}_{\text {year }}{ }^{-1}$, but ACE-FTS $\mathrm{CO}_{2}$ has a high degree of temporal stability and can be used to detect this level of change. This is possible due to the self-calibrating nature of the solar occultation measurements.

As discussed in Sect. 3.2 (Fig. 12), biases versus altitude between 7 and $12 \mathrm{~km}$ are on the order of $9 \mathrm{ppm}$. Natural variations in this altitude range can reach 8 ppm in April 2010 at $65^{\circ} \mathrm{N}$ (according to HIPPO data). The vertical gradient in the boreal early spring is mostly due to the strong seasonal cycle in the Arctic mid-troposphere.

Biases versus latitude (maximum bias difference of $8.8 \mathrm{ppm}$ between the tropics and the southern polar region shown in Fig. 13) approaches the natural latitude gradient of $9.2 \mathrm{ppm}$ at $5.5 \mathrm{~km}$ in April 2010 (maximum and minimum at $85^{\circ} \mathrm{N}$ and $65^{\circ} \mathrm{S}$, respectively, according to HIPPO). ACE-FTS $\mathrm{CO}_{2}$ bias differences between southern high latitudes and northern mid-latitudes are on the order of $5 \mathrm{ppm}$ at $12 \mathrm{~km}$ (Fig. 14). According to in situ observations (Fig. 15, left panel), the latitude gradient between $45^{\circ} \mathrm{N}$ and $65^{\circ} \mathrm{S}$ at $10 \mathrm{~km}$ in boreal spring is $6 \mathrm{ppm}$. Figure 15 shows the 6 and $4 \mathrm{ppm}$ gradient at 9.5 and $10.5 \mathrm{~km}$, respectively, using differences between CONTRAIL and HIPPO observations from these two latitude bands. According to the ACE-FTS retrievals, the gradients are of 5, 6, 4, and $1 \mathrm{ppm}$ at 9.5, 10.5, $11.5,12.5 \mathrm{~km}$, respectively. The decreasing latitudinal gradient with height is expected at $12.5 \mathrm{~km}$ because both latitude bands are in the stratosphere at this altitude, where the gradients are smaller because they are not as sensitive to local sources and sinks as the upper troposphere. This latitudinal gradient disappears toward the end of boreal summer at $10 \mathrm{~km}$ due to the strong biospheric uptake at northern extratropical latitudes (Fig. 15, right panel). Thus the latitudinal gradient has a seasonal variation. The low $\mathrm{CO}_{2}$ bias 
of ACE-FTS due to tangent height offsets also appears in Fig. 15. Also, the consistency between boreal summer and spring $\mathrm{CO}_{2}$ VMR near the tropopause in the ACE-FTS data is encouraging.

The vast majority of ACE-FTS $\mathrm{CO}_{2}$ profiles which extend below $6.5 \mathrm{~km}$ are located in the Antarctic, which is a region of no flux, and the Southern Ocean, which has one of the smallest posterior errors of any region (Pak and Prather, 2001; Baker et al., 2006). This presents a challenge for constraining fluxes from satellite-based upper tropospheric profile measurements. The present scientific value of the ACE-FTS $\mathrm{CO}_{2}$ data lies mostly in providing continuous global monitoring of the vertical profile in the upper troposphere and lower stratosphere with good temporal stability and small retrieval uncertainties in the stratosphere as expected from a solar occultation FTS. Taking annual means further magnifies the difference in uncertainties between the troposphere and stratosphere because clouds limit the fraction of occultations which provide tropospheric data.

Acknowledgements. This work was supported by the Canadian Space Agency through a memorandum of understanding with Environment Canada. We acknowledge Laurence Rothman (Harvard-Smithsonian Center for Astrophysics) for guidance in converting between line intensities reported with different units. Lin Huang (Environment Canada) helped us understand the different standards used in isotopic measurements. Toshinobu Machida (National Institute for Environmental Studies, Japan), Hidekazu Matsueda, and Yousuke Sawa (both at Meteorological Research Institute, Japan) are acknowledged for providing the CONTRAIL data. We acknowledge Britt Stephens (National Center for Atmospheric Research) for providing guiding comments regarding HIPPO $\mathrm{CO}_{2}$ data and Steve Wofsy as HIPPO lead principal investigator. We thank Carl Brenninkmeijer for his suggestions on an earlier draft of this manuscript and, together with Tanja Schuck (both at Max Planck Institute for Chemistry), for providing the CARIBIC data.

Edited by: H. Worden

\section{References}

Baker, D. F., Law, R. M., Gurney, K. R., Rayner, P., Peylin, P., Denning, A. S., Bousquet, P., Bruhwiler, L., Chen, Y.-H., Ciais, P., Fung, I. Y., Heimann, M., John, J., Maki, T., Maksyutov, S., Masarie, K., Prather, M., Pak, B., Taguchi, S., and Zhu, Z.: TransCom 3 inversion intercomparison: Impact of transport model errors on the interannual variability of regional $\mathrm{CO}_{2}$ fluxes, 1988-2003, Global Biogeochem. Cy., 20, GB1002, doi:10.1029/2004GB002439, 2006.

Baranov, Y. I., Buryak, I. A., Lokshtanov, S. E., Lukyanchenko, V. A., and Vigasin, A. A.: $\mathrm{H}_{2} \mathrm{O}-\mathrm{N}_{2}$ collision-induced absorption band intensity in the region of the $\mathrm{N}_{2}$ fundamental ab initio investigation of its temperature dependence, Phil. Trans. R. Soc. A, 370, 2691-2709, 2012.
Beagley, S. R., Boone, C. D., Fomichev, V. I., Jin, J. J., Semeniuk, K., McConnell, J. C., and Bernath, P. F.: First multi-year occultation observations of $\mathrm{CO} 2$ in the MLT by ACE satellite: observations and analysis using the extended CMAM, Atmos. Chem. Phys., 10, 1133-1153, doi:10.5194/acp-10-1133-2010, 2010.

Berk, A., Anderson, G. P., Acharya, P. K., Bernstein, L. S., Muratov, L., Lee, J., Fox, M., Adler-Golden, S. M., Chetwynd, J. H., Hoke, M. L., Lockwood, R. B., Gardner, J. A., Cooley, T. W., Borel, C. C., and Lewis, P. E.: MODTRAN ${ }^{\mathrm{TM}}$ 5, A reformulated atmospheric band model with auxiliary species and practical multiple scattering options: Update, Proc. SPIE 5806, 662-667, 2005.

Boone, C. D., Nassar, R., Walker, K. A., Rochon, Y., McLeod, S. D., Rinsland, C. P., and Bernath, P. F.: Retrievals for the atmospheric chemistry experiment Fourier-transform spectrometer, Appl. Opt., 44, 7218-7231, 2005.

Boone, C. D., Walker, K. A., and Bernath, P. F.: Version 3 retrievals for the Atmospheric Chemistry Experiment Fourier Transform Spectrometer (ACE-FTS), in: The Atmospheric Chemistry Experiment ACE at 10, A Solar Occultation Anthology, edited by: Bernath, P. F., A. Deepak Publishing, Hampton, VA, 103-127, 2013.

Châteauneuf, F., Soucy, M.-A., and Fortin, S.: ACE-FTS instrument: after two years on-orbit, Proc. SPIE, 5883, doi:10.1117/12.626663, 2005.

Clapp, M. L., Niedziela, R. F., Richwine, L. J., Dransfield, T., and Miller, R. E., and Worsnop, D. R.: Infrared spectroscopy of sulfuric acid/water aerosols: Freezing characteristics, J. Geophys. Res., 102, 8899-8907, 1997.

Côté, J., Desmarais, J.-G., Gravel, S., Méthot, A., Patoine, A., Roch, M., and Staniforth, A.: The Operational CMC-MRB Global Environmental Multiscale (GEM) Model, Part II: Results, Mon. Weather Rev., 126, 1397-1418, 1998.

Daube, B. C., Boering, K. A., Andrews, A. E., and Wofsy, S. C.: A high-precision fast-response airborne $\mathrm{CO}_{2}$ analyzer for in situ sampling from the surface to the middle stratosphere, J. Atmos. Oceanic Technol., 19, 1532-1543, 2002.

Doeringer, D., Eldering, A., Boone, C. D., González Abad, G., and Bernath, P. F.: Observation of sulfate aerosols and $\mathrm{SO}_{2}$ from the Sarychev volcanic eruption using data from the Atmospheric Chemistry Experiment (ACE), J. Geophys. Res., 117, D03203, doi:10.1029/2011JD016556, 2012.

Emmert, J. T., Stevens, M. H., Bernath, P. F., Drob, D. P., and Boone, C. D.: Observations of increasing carbon dioxide concentration in Earth's thermosphere, Nat. Geosci., 5, 868-871, 2012.

Fischer, H., Birk, M., Blom, C., Carli, B., Carlotti, M., von Clarmann, T., Delbouille, L., Dudhia, A., Ehhalt, D., Endemann, M., Flaud, J. M., Gessner, R., Kleinert, A., Koopman, R., Langen, J., López-Puertas, M., Mosner, P., Nett, H., Oelhaf, H., Perron, G., Remedios, J., Ridolfi, M., Stiller, G., and Zander, R.: MIPAS: an instrument for atmospheric and climate research, Atmos. Chem. Phys., 8, 2151-2188, doi:10.5194/acp-8-2151-2008, 2008.

Foucher, P. Y.: Détermination de profils verticaux de concentration en $\mathrm{CO}_{2}$ atmosphérique à partir d'observations spatiales. Application aux données en occultation solaire de l'instrument ACE-FTS sur SCISAT 1. PhD thesis, Université de Paris VI, 198 pp., 2009.

Foucher, P. Y., Chédin, A., Dufour, G., Capelle, V., Boone, C. D., and Bernath, P.: Technical Note: Feasibility of $\mathrm{CO}_{2}$ profile retrieval from limb viewing solar occultation made by 
the ACE-FTS instrument, Atmos. Chem. Phys., 9, 2873-2890, doi:10.5194/acp-9-2873-2009, 2009.

Foucher, P. Y., Chédin, A., Armante, R., Boone, C., Crevoisier, C., and Bernath, P.: Carbon dioxide atmospheric vertical profiles retrieved from space observation using ACE-FTS solar occultation instrument, Atmos. Chem. Phys., 11, 2455-2470, doi:10.5194/acp-11-2455-2011, 2011.

Froyd, K. D., Murphy, D. M., Sanford, T. J., Thomson, D. S., Wilson, J. C., Pfister, L., and Lait, L.: Aerosol composition of the tropical upper troposphere, Atmos. Chem. Phys., 9, 4363-4385, doi:10.5194/acp-9-4363-2009, 2009.

García-Comas, M., Funke, B., López-Puertas, M., BermejoPantaleón, D., Glatthor, N., von Clarmann, T., Stiller, G., Grabowski, U., Boone, C. D., French, W. J. R., Leblanc, T., López-González, M. J., and Schwartz, M. J.: On the quality of MIPAS kinetic temperature in the middle atmosphere, Atmos. Chem. Phys., 12, 6009-6039, doi:10.5194/acp-12-6009-2012, 2012.

Gille, J., Barnett, J., Arter, P., Barker, M., Bernath, P., Boone, C., Cavanaugh, C., Chow, J., Coffey, M., Craft, J., Craig, C., Dials, M., Dean, V., Eden, T., Edwards, D. P., Francis, G., Halvorson, C., Harvey, L., Hepplewhite, C., Khosravi, R., Kinnison, D., Krinsky, C., Lambert, A., Lee, H., Lyjak, L., Loh, J., Mankin, W., Massie, S., McInerney, J., Moorhouse, J., Nardi, B., Packman, D., Randall, C., Reburn, J., Rudolf, W., Schwartz, M., Serafin, J., Stone, K., Torpy, B., Walker, K., Waterfall, A., Watkins, R., Whitney, J., Woodard, D., and Young, G.: High resolution dynamics limb sounder: experiment overview, recovery and validation of initial temperature data, J. Geophys. Res., 113, D16S43, doi:10.1029/2007JD008824, 2008.

Goldman, A., Tipping, R. H., Ma, Q., Boone, C. D., Bernath, P. F., Demoulin, P., Hase, F., Schneider, M., Hannigan, J. W., Coffey, M. T., and Rinsland, C. P.: On the line parameters for the $\mathrm{X}^{1} \Sigma_{g}^{+}$ (1-0) infrared quadrupolar transitions of ${ }^{14} \mathrm{~N}_{2}$, J. Quant. Spectrosc. Radiat. Transfer, 103, 168-174, 2007.

Gordley, L., Burton, J., Marshall, B. T., McHugh, M., Deaver, L., Nelsen, J., Russell, J. M., and Bailey, S.: High precision measurements by solar imaging during occultation: results from SOFIE, Appl. Opt., 48, 4814-4825, 2009.

Hofmann, D. J., Butler, J. H., and Tans, P. P.: A new look at atmospheric carbon dioxide, Atmos. Environ., 43, 2084-2086, 2009.

Kawagucci, S., Tsunogai, U., Kudo, S., Nakagawa, F., Honda, H., Aoki, S., Nakazawa, T., Tsutsumi, M., and Gamo, T.: Longterm observation of mass-independent oxygen isotope anomaly in stratospheric $\mathrm{CO}_{2}$, Atmos. Chem. Phys., 8, 6189-6197, doi:10.5194/acp-8-6189-2008, 2008.

Keppel-Aleks, G., Wennberg, P. O., Washenfelder, R. A., Wunch, D., Schneider, T., Toon, G. C., Andres, R. J., Blavier, J.-F., Connor, B., Davis, K. J., Desai, A. R., Messerschmidt, J., Notholt, J., Roehl, C. M., Sherlock, V., Stephens, B. B., Vay, S. A., and Wofsy, S. C.: The imprint of surface fluxes and transport on variations in total column carbon dioxide, Biogeosciences, 9, 875891, doi:10.5194/bg-9-875-2012, 2012.

Lafferty, W. J., Solodov, A. M., Weber, A., Olson, W. B., and Hartmann, J.-M.: Infrared collision-induced absorption by $\mathrm{N}_{2}$ near $4.3 \mu \mathrm{m}$ for atmospheric applications: measurements and empirical modeling, Appl. Opt., 35, 5911-5917, 1996.

Machida, T., Matsueda, H., Sawa, Y., Nakagawa, Y., Hirotani, K., Kondo, N., Goto, K., Ishikawa, K., Nakazawa, T., and Ogawa, T.:
Worldwide measurements of atmospheric $\mathrm{CO}_{2}$ and other trace gas species using commercial airlines, J. Atmos. Oceanic Technol., 25, 1744-1754, doi:10.1175/2008JTECHA1082.1, 2008.

Malathy Devi, V., Rinsland, C. P., and Benner, D. C.: Absolute intensity measurements of $\mathrm{CO}_{2}$ bands in the $2395-2680 \mathrm{~cm}^{-1}$ region, Appl. Opt., 23, 4067-4075, 1984.

Melo, S. M. L., Walker, K. A., and Degenstein, D.: The Chemical and Aerosol Sounding Satellite (CASS) mission as a solution for global climate quality atmospheric composition measurements, in: The Atmospheric Chemistry Experiment ACE at 10: A Solar Occultation Anthology, edited by Bernath, P. F., A. Deepak Publishing, Hampton, VA, USA), 323-330, 2013.

Menoux, V., Le Doucen, R., Boulet, C., Roblin, A., and Bouchardy, A. M.: Collision-induced absorption in the fundamental band of $\mathrm{N}_{2}$ : temperature dependence of the absorption for $\mathrm{N}_{2}-\mathrm{N}_{2}$ and $\mathrm{N}_{2}-\mathrm{O}_{2}$ pairs, Appl. Opt., 32, 263-268, 1993.

Moreau, G.: Etude en temperature et modélisation de l'absorption induite par collision dans les régions des bandes fondamentales pour les mélanges des gaz $\mathrm{N}_{2}$ et $\mathrm{O}_{2}$. $\mathrm{PhD}$ thesis, Université de Rennes 1, 127 pp., 1999.

Murphy, D. M., Cziczo, D. J., Froyd, K. D., Hudson, P. K., Matthew, B. M., Middlebrook, A. M., Peltier, R. E., Sullivan, A., Thomson, D. S., and Weber, R. J.: Single-particle mass spectrometry of tropospheric aerosol particles, J. Geophys. Res., 111, D23S32, doi:10.1029/2006JD007340, 2006.

Nash, K. L., Sully, K. J., and Horn, A. B.: Observations on the interpretation and analysis of sulfuric acid hydrate infrared spectra, J. Phys. Chem. A, 105, 9422-9426, 2001.

Pak, B. C. and Prather, M. J.: $\mathrm{CO}_{2}$ source inversions using satellite observations of the upper troposphere, Geophys. Res. Lett., 28, 4571-4574, 2001.

Qaddouri, A. and Lee, V.: The Canadian Global Environmental Multiscale model on the Yin-Yang grid system, Q. J. R. Meteorol. Soc., 137, 1913-1926, doi:10.1002/qj.873, 2011.

Rice, A. L., Tyler, S. C., McCarthy, M. C., Boering, K. A., and Atlas, E.: Carbon and hydrogen isotopic compositions of stratospheric methane: 1. High-precision observations from the NASA ER-2 aircraft, J. Geophys. Res., 108, 4460, doi:10.1029/2002JD003042, 2003.

Richard, C., Gordon, I. E., Rothman, L. S., Abel, M., Frommhold, L., Gustafsson, M., Hartmann, J.-M., Hermans, C., Lafferty, W. J., Orton, G. S., Smith, K. M., and Tran, H.: New section of the HITRAN database: Collision-induced absorption (CIA), J. Quant. Spectrosc. Radiat. Transfer, 113, 1276-1285, 2012.

Rinsland, C. P., Chiou, L. S., Boone, C., and Bernath, P.: Carbon dioxide retrievals from Atmospheric Chemistry Experiment solar occultation measurements, J. Geophys. Res., 115, D03105, doi:10.1029/2009JD012081, 2010.

Rothman, L. S., Gordon, I. E., Babikov, Y., Barbe, A., Benner, D. C., Bernath, P. F., Birk, M., Bizzocchi, L., Boudon, V., Brown, L. R., Campargue, A., Chance, K., Cohen, E. A., Coudert, L. H., Devi, V. M., Drouin, B. J., Fayt, A., Flaud, J. M., Gamache, R. R., Harrison, J. J., Hartmann, J. M., Hill, C., Hodges, J. T., Jacquemart, D., Jolly, A., Lamouroux, J., Le Roy, R. J., Li, G., Long, D. A., Lyulin, O. M., Mackie, C. J., Massie, S. T., Mikhailenko, S., Müller, H. S. P., Naumenko, O. V., Nikitin, A. V., Orphal, J., Perevalov, V., Perrin, A., Polovtseva, E. R., Richard, C., Smith, M. A. H., Starikova, E., Sung, K., Tashkun, S., Tennyson, J., Toon, G. C., Tyuterev, V. G., and Wagner, G.: The HITRAN 2012 
molecular spectroscopic database, J. Quant. Spectrosc. Radiat. Transfer, 130, 4-50, 2013.

Schuck, T. J., Brenninkmeijer, C. A. M., Slemr, F., Xueref-Remy, I., and Zahn, A.: Greenhouse gas analysis of air samples collected onboard the CARIBIC passenger aircraft, Atmos. Meas. Tech., 2, 449-464, doi:10.5194/amt-2-449-2009, 2009.

Schwartz, M. J., Lambert, A., Manney, G. L., Read, W. G., Livesey, N. J., Froidevaux, L., Ao, C. O., Bernath, P. F., Boone, C. D., Cofield, R. E., Daffer, W. H., Drouin, B. J., Fetzer, E. J., Fuller, R. A., Jarnot, R. F., Jiang, J. H., Jiang, Y. B., Knosp, B. W., Krüger, K., Li, J.-L. F., Mlynczak, M. G., Pawson, S., Russell III, J. M., Santee, M. L., Snyder, W. V., Stek, P. C., Thurstans, R. P., Tompkins, A. M., Wagner, P. A., Walker, K. A., Waters, J. W., and Wu, D. L.: Validation of the Aura Microwave Limb Sounder temperature and geopotential height measurements, J. Geophys. Res., 113, D15S11, doi:10.1029/2007JD008783, 2008.

Sheese, P. E., Strong, K., Llewellyn, E. J., Gattinger, R. L., Russell III, J. M., Boone, C. D., Hervig, M. E., Sica, R. J., and Bandoro, J.: Assessment of the quality of OSIRIS mesospheric temperatures using satellite and ground-based measurements, Atmos. Meas. Tech., 5, 2993-3006, doi:10.5194/amt-5-2993-2012, 2012.

Sica, R. J., Izawa, M. R. M., Walker, K. A., Boone, C., Petelina, S. V., Argall, P. S., Bernath, P., Burns, G. B., Catoire, V., Collins, R. L., Daffer, W. H., De Clercq, C., Fan, Z. Y., Firanski, B. J., French, W. J. R., Gerard, P., Gerding, M., Granville, J., Innis, J. L., Keckhut, P., Kerzenmacher, T., Klekociuk, A. R., Kyrö, E., Lambert, J. C., Llewellyn, E. J., Manney, G. L., McDermid, I. S., Mizutani, K., Murayama, Y., Piccolo, C., Raspollini, P., Ridolfi, M., Robert, C., Steinbrecht, W., Strawbridge, K. B., Strong, K., Stübi, R., and Thurairajah, B.: Validation of the Atmospheric Chemistry Experiment (ACE) version 2.2 temperature using ground-based and space-borne measurements, Atmos. Chem. Phys., 8, 35-62, doi:10.5194/acp-8-35-2008, 2008.
Sioris, C. E., Boone, C. D., Bernath, P. F., Zou, J., McElroy, C. T., McLinden, C. A.: ACE observations of aerosol in the upper troposphere and lower stratosphere from the Kasatochi volcanic eruption, J. Geophys. Res., 115, D00L14, doi:10.1029/2009JD013469, 2010.

Stratospheric Processes and their Role in Climate (SPARC): SPARC Report No. 2: SPARC Assessment of Upper Tropospheric and Stratospheric Water Vapour, WCRP No. 113, WMO/TD-No. 1043, 312 pp., 2000.

Teffo, J.-L., Daumont, L., Claveau, C., Valentin, A., Tashkun, S. A., and Perevalov, V. I.: Infrared spectra of the ${ }^{16} \mathrm{O}^{12} \mathrm{C}^{17} \mathrm{O}$ and ${ }^{16} \mathrm{O}^{12} \mathrm{C}^{18} \mathrm{O}$ species of carbon dioxide: The region $500-1500$ $\mathrm{cm}^{-1}$, J. Mol. Spectrosc., 213, 145-152, 2002.

Teffo, J.-L., Daumont, L., Claveau, C., Valentin, A., Tashkun, S. A., and Perevalov, V. I.: Infrared spectra of the ${ }^{16} \mathrm{O}^{12} \mathrm{C}^{17} \mathrm{O}$ and ${ }^{16} \mathrm{O}^{12} \mathrm{C}^{18} \mathrm{O}$ species of carbon dioxide: II. The $1500-3000 \mathrm{~cm}^{-1}$ region, J. Mol. Spectrosc., 219, 271-281, 2003.

Toth, R. A.: Line positions and strengths of $\mathrm{CO}_{2}$ in the 1200-1430$\mathrm{cm}^{-1}$ region, Appl. Opt., 24, 261-274, 1985.

Wiegel, A. A., Cole, A. S., Hoag, K. J., Atlas, E. L., Schauffler, S. M., and Boering, K. A.: Unexpected variations in the triple oxygen isotope composition of stratospheric carbon dioxide, Proc. Natl. Acad. Sci., 110, 17680-17685, doi:10.1073/pnas.1213082110, 2013.

Wofsy, S. C. et al.: HIAPER Pole-to-Pole Observations (HIPPO): fine-grained, global-scale measurements of climatically important atmospheric gases and aerosols, Phil. Trans. R. Soc. A, 369, 2073-2086, doi:10.1098/rsta.2010.0313, 2011.

Wunch, D., Toon, G. C., Blavier, J.-F. L., Washenfelder, R. A., Notholt, J., Connor, B. J., Griffith, D. W. T., Sherlock, V., and Wennberg, P. O.: The Total Carbon Column Observing Network, Phil. Trans. R. Soc. A, 369, 2087-2112, doi:10.1098/rsta.2010.0240, 2011. 